Süleyman Demirel Üniversitesi Fen Edebiyat Fakültesi Fen Dergisi

Süleyman Demirel University Faculty of Arts and Sciences Journal of Science

2021, 16(2): 368-384

DOI: $10.29233 /$ sdufeffd. 953182

Atıf için / For Citation: M. Şahan, "Yapay sinir ağları ve Angström-Prescott denklemleri kullanılarak Gaziantep, Antakya ve Kahramanmaraş için global güneş radyasyonu tahmini”, Süleyman Demirel Üniversitesi Fen Edebiyat Fakültesi Fen Dergisi, 16(2), 368384, 2021.

Araştırma Makalesi

\title{
Yapay Sinir Ağları ve Angström-Prescott Denklemleri Kullanılarak Gaziantep, Antakya ve Kahramanmaraş İçin Global Güneş Radyasyonu Tahmini
}

\author{
Muhittin ŞAHAN ${ }^{* 1}$

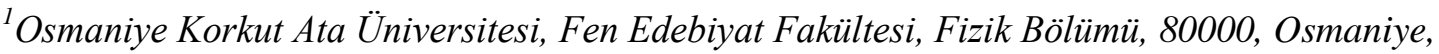 \\ Türkiye
}

*yazışılan yazar e-posta: muhittinsahan@osmaniye.edu.tr

(Alınış: 16.06.2021, Kabul: 05.07.2021, Yayımlanma: 25.11.2021)

Öz: Bu çalışmada, Akdeniz bölgesinin doğusundan seçilen Gaziantep $\left(37^{\circ} .06 \mathrm{~K}, 37^{\circ} .35 \mathrm{D}\right.$, $750 \mathrm{~m})$, Antakya $\left(36^{\circ} .15 \mathrm{~K}, 36^{\circ} .08 \mathrm{D}, 100 \mathrm{~m}\right)$ ve Kahramanmaraş $\left(37^{\circ} .35 \mathrm{~K}, 36^{\circ} .55 \mathrm{D}, 572 \mathrm{~m}\right)$ bölgeleri için yatay bir yüzeydeki aylık olarak ortalama global güneş 1şınımını tahmin etmek için yapay sinir ağı (YSA) modeli ve güneşlenme süresine bağlı Angström-Prescott tipi eşitlikler kullanılmıştır. Bu amaçla, ölçülen veriler kullanılarak YSA modeli ve güneşlenme saatlerine ilişkin Angström-Prescott tipi denklemler uygulanmıştır. İlk olarak, modelleme için en iyi YSA modeli için transfer fonksiyonu olarak Hyperbolic Tangent Sigmoidli (tansig) iki gizli katmanı ve lineer transfer fonksiyonu kullanan bir çıkış katmanlı ileri beslemeli geri yayılımlı bir modeli kullanılmıştır. Levenberg-Marquardt geri yayılım eğitim algoritması (trainlm) YSA modelinde eğitim algoritması olarak seçilmiştir. Devlet Meteoroloji Genel Müdürlüğ̈̈'nden alınan on beş y1llık (1993-2007) ölçülmüş meteorolojik veriler ağın eğitilmesi (on bir yıl) ve test edilmesi (dört yıl) için kullanılmıştır. İkinci olarak, aylık ortalama güneşlenme süresi (saat), aylık ortalama sicaklık $\left({ }^{\circ} \mathrm{C}\right)$, bağıl nem ve güneş deklinasyon açısı $(\delta)$ gibi parametreler kullanılarak aylık olarak yıllık global güneş radyasyonunun tahmin edilmesi için beş farklı Angström-Prescott tipi regresyon modeli (M1-5) de geliştirilmiştir. YSA'dan ve Angström-Prescott tipi denklemlerden tahmin edilen veriler ile ölçülen veriler $\mathrm{R}^{2}$, RMSE, MAPE ve MSE gibi dört farklı istatistiksel yöntem kullanılarak karşılaştırılmıştır. YSA modeli için $\mathrm{R}^{2}$, RMSE, MAPE ve MSE istatistiksel göstergeleri sırasıyla Gaziantep için 0.990, 0.586, 4.105 ve 0.343 , Antakya için $0.997,0.287,2.584$, ve 0.083 ve Kahramanmaraş için 0.997, $0.414,2.445$ ve 0.171 olarak bulunmuştur. Beş farklı Angström-Prescott modeli (M1-M5) modeli için $\mathrm{R}^{2}$, RMSE ve MSE performans göstergelerine göre, Gaziantep ve Kahramanmaraş için M3 modeli, Antakya için ise M5 modeli en iyi performans1 göstermiştir. İstatistiksel hata sonuçlarından görülebileceği gibi, ANN ve Angström-Prescott tipi modellerden tahmini global güneş radyasyon verileri, ölçülen meteorolojik değerlerle iyi bir uyum içindedir. Geliştirilen YSA ve Angström-Prescott tip modellerin diğer yerleşim yerleri için de tahmin etmede kullanılabileceğini önermekteyiz.

Anahtar kelimeler: Global güneş 1şınımı, Güneş 1şınım tahmin modelleri, Yapay sinir ağları Güneşlenme süresi, Açıklık indeksi, Angström-Prescott eşitliği, Korelasyon modelleri 


\title{
Estimation of Solar Radiation for Gaziantep, Antakya and Kahramanmaraş Using Artificial Neural Network and Angström-Prescott Equations
}

\begin{abstract}
In this study, we estimated monthly average global solar radiation on a horizontal surface for selected regions of Gaziantep $\left(37^{\circ} .06 \mathrm{~N}, 37^{\circ} .35 \mathrm{E}, 750 \mathrm{~m}\right)$, Antakya $\left(36^{\circ} .15 \mathrm{~N}\right.$, $\left.36^{\circ} .08 \mathrm{E}, 100 \mathrm{~m}\right)$, and Kahramanmaraş $\left(37^{\circ} .35 \mathrm{~N}, 36^{\circ} .55 \mathrm{E}, 572 \mathrm{~m}\right)$ from the east of the Mediterranean region. For this purpose, an artificial neural network (ANN) model and Angström-Prescott type equations related to sunshine hosurs were applied using the data measured. Firstly, a multi-layer feed-forward back-propagation model containing two hidden layers with tangent sigmoid (tansig) as the transfer function and one output layer with utilized a linear transfer function for the best ANN model was used for the modelling. LevenbergMarquardt back propagation training algorithm (trainlm) was chosen as the training algorithm in the ANN model. A period of fifteen years (1993-2007) meteorological data taken from the Turkish State Meteorological Service were used for training (eleven years) and testing (four years) the network. Secondly, five Angström-Prescott type regression models (M1-5) were also used for estimating the monthly annual global solar radiation using parameters such as monthly average sunshine duration (hour), monthly average temperature $\left({ }^{\circ} \mathrm{C}\right)$, relative humidity and solar declination angle $(\delta)$. Estimated data from ANN and Angström-Prescott type equations were compared with measured data using four different statistical methods such as $\mathrm{R}^{2}$, RMSE, MAPE and MSE. For the ANN model, $\mathrm{R}^{2}, \mathrm{RMSE}, \mathrm{MAPE}$ and MSE statically indicators were found to be $0.990,0.586,4.105$ and 0.343 for Gaziantep, 0.997, 0.287, 2.584, and 0.083 for Antakya, and 0.997, 0.414, 2.445 and 0.171 for Kahramanmaraş, respectively. For five different AngströmPrescott models (M1-M5) models, M3 model is the best performance for Gaziantep and Kahramanmaraş, while M5 model is the best performing for Antakya, according $\mathrm{R}^{2}$, RMSE and MSE MSE performance indicators. As can be seen from the statistical error results, the estimated global solar radiation data from both ANN and Angström-Prescott type models are in reasonable agreement with the actual meteorological values. We suggest that the developed both ANN and Angström-Prescott type models can also be used to predict solar radiation another location.
\end{abstract}

Key words: Global solar radiation, Solar radiation estimation models, Artificial neural network, Sunshine hours, Clearness index, Angström-Prescott equation, Correlation models,

\section{Giriş}

Temiz enerji ve temiz su yeryüzünde yaşayan tüm canlılar için en temel iki ana ihtiyaç kaynağıdır ve birbiriyle yakından ilişkilidir. Temiz enerji kaynağı olarak güneş enerjisi en eski bir enerji kaynağıdır ve neredeyse tüm fosil ve yenilenebilir enerji türleri için bir temel unsurdur. Güneş enerjisinin üretilmesi ve pek çok alanda kullanılması son zamanlarda çok yaygınlaşmıştır. Enerji üretimi için tasarlanan malzemeleri tasarlarken doğayı kirleten hidrokarbon bazlı enerjiye olan bağımlılığını azaltmak gerekmektedir. $\mathrm{Bu}$ nedenle, güneşten enerji elde etme ve bu enerjiyi depolayabilme tekniklerinin tasarlanması ve geliştirilmesi oldukça önemlidir. Bugün güneş enerjisinden en iyi şekilde faydalanabilmek için pek çok ülke bu alanda büyük yatırımlar yapmaktadırlar $[1,2]$. Türkiye'de de uzun yıllardır ekonomik ve sosyal kalkınmanın yanı sıra ve yaşam kalitesinin iyileştirilmesi için güneş enerjisinden yararlanma amacıyla özel ve kamu kurumlarında önemli çalışmalar yapılmaktadır [3-5].

Dünyada pek çok bölgede, coğrafi konuma bağlı olarak güneş radyasyonunun hassas bir şekilde ölçülmesi, meteorolojik tahminlerin, tarımsal çalışmaların, doğa bilimlerinin ve pek çok mühendislik alanlarındaki uygulamalarının tasarımı ve incelenmesi için oldukça önemlidir. Ne yazık ki, gelişmiş ülkeler dışındaki, global güneş radyasyonunu 
günlük olarak ölçen çok az sayıda meteoroloji istasyonu bulunmaktadır. Global güneş radyasyonun ölçülemediği istasyonlar için genel olarak günlük güneşlenme süresi gibi ölçülen diğer meteorolojik parametrelerden global güneş radyasyonunu tahmin etmek için yapay sinir ağları ya da teorik ve ampirik formüller kullanılarak pek çok korelasyon modelleri geliştirilmiştir. Bunun için güneşlenme süresi, atmosfer dişı 1şınım, sıcaklık, bağıl nem gibi daha kolay elde edilebilen meteorolojik parametreler kullanılarak aylık ortalama güneş radyasyonu miktarlarını tahmin edilmeye çalışılmıştır [1, 2, 5-15]. Bu çalışmada, aşağıda detaylı olarak açıklandığı gibi meteorolojik veriler kullanılarak yapay sinir ağları ve ampirik formüller ile bir birine yakın üç farklı bölge için aylık olarak global güneş enerjisinin tahmini için modeller geliştirilmiştir.

\section{Materyal ve Metot}

$\mathrm{Bu}$ çalışmada, Türkiye'nin güneş enerjisi bakımından oldukça iyi durumda olan Akdeniz iklim bölgesinin doğusunda yer alan Gaziantep (Boy $=37^{\circ} .06 \mathrm{~K}$, Enl=37 $.35 \mathrm{D}$, $750 \mathrm{~m})$, Antakya $\left(\right.$ Boy $\left.=36^{\circ} .15 \mathrm{~K}, \quad \mathrm{Enl}=36^{\circ} .08 \mathrm{D}, 100 \mathrm{~m}\right)$ ve Kahramanmaraş $\left(\mathrm{Boy}=37^{\circ} .35 \mathrm{~K}, \mathrm{Enl}=36^{\circ} .55 \mathrm{D}, 572 \mathrm{~m}\right)$ yerleşim yerleri için aylık olarak ortalama güneş 1şınım şiddetini tahmin edilmiştir. Güneş 1 şınım şiddetini tahmin edilmesinde Türkiye Meteoroloji Genel Müdürlüğü’nden (MGM) alınan 1993-2007 (15 yıl) yılları arasında bulunan bazı meteorolojik ve coğrafik veriler kullanılmıştır. Bu veriler, günlük olarak güneşlenme süresi, ortalama sıcaklık, bağıl nem, bulutluluk, buhar basıncı, ölçülmüş toplam global güneşlenme şiddeti gibi meteorolojik veriler ile enlem, boylam, yükseklik gibi coğrafik verileri içermektedir.

Gaziantep, Antakya ve Kahramanmaraş bölgeleri için aylık olarak yıllık güneş 1şınım şiddeti tahmin edilmesinde, yapay sinir ağları metodu (YSA) [5,16] ile doğrusal regresyon ifadesi olarak ifade edilen Angström-Prescott ampirik formüller kullanan modeller [6,7] geliştirilmiştir. Her iki yöntem de, güneş 1şınım şiddetinin tahmin edilmesinde oldukça yaygın olarak kullanılmaktadır. Bu çalışmada, Gaziantep, Antakya ve Kahramanmaraş bölgeleri için güneş 1 şınım şiddetini tahmin etmek için en uygun modeller olan YSA ve Angström tipi modeller tespiti ve bu modellerden elde edilen sonuçlar kısaca verilecektir.

\subsection{Yapay Sinir A ğı (YSA) modeli}

Yapay zeka yöntemlerinden biri olan Yapay Sinir Ağları (YSA), biyolojik sinir sistemlerinin özelliklerine dayanan bir hesaplama aracıdır ve çok karmaşık problemleri bilgisayar yardımıyla çözmek amacıyla geliştirilen, ağırlıklı bağlantılar aracılığıyla birbirine bağlanan çok sayıda işlem elemanlarından oluşan (Şekil 1) ve her biri kendi belleğine sahip işlem elemanlarından oluşan bir veri işleme tekniğidir [5,17]. İnsan beyni gibi, öğrenme hatırlama ve genelleme yeteneğine sahip olan YSA metotlarının en önemli avantajları, enlem, boylam, sıcaklık, nem, güneşlenme süresi, basınç gibi mevcut olan sayısal veriler (Şekil 2) arasındaki tam olarak tanımlanamayan ilişkileri belirlemek ve doğrusal olmayan problem çözümlerini sağlamak amaciyla, bunlara ait tahmin modelleri geliştirme yeteneğine sahiptirler [5,18].

YSA'daki mimari yapı nöronlar arasındaki bağlantıları tanımlar ve girdi katmanı $\left(I_{n}\right)$, bir ya da daha fazla gizli (ara) katmanı ve çıktı katmanı olmak üzere üç katmandan oluşmaktadır. Şekil 1'de görüldüğü gibi gizli katman, toplama ve aktivasyon (etkinlik) fonksiyonlarından oluşur ve aldığı bilgileri sinir hücresine iletirler [19]. 
Ağırlıklar $\left(w_{n}\right)$, yapay sinir hücresine gelen bilgilerin önemini ve hücre üzerindeki etkisini gösterir. Toplama fonksiyonu, girdi katmanlarından hücreye gelen ve ağırlıkları belirlenen net girdiyi hesaplar. Aktivasyon fonksiyonu, toplama fonksiyonundan gelen net girdiyi işleyerek çıktıyı belirler. Çıktı elemanı ise aktivasyon fonksiyonundan çıkan sonucun dış dünyaya gönderildiği yerdir. Çıkış katmanındaki nöron sayısı, ağa giren her verinin çıkış sayısı kadardır [3-5,17].

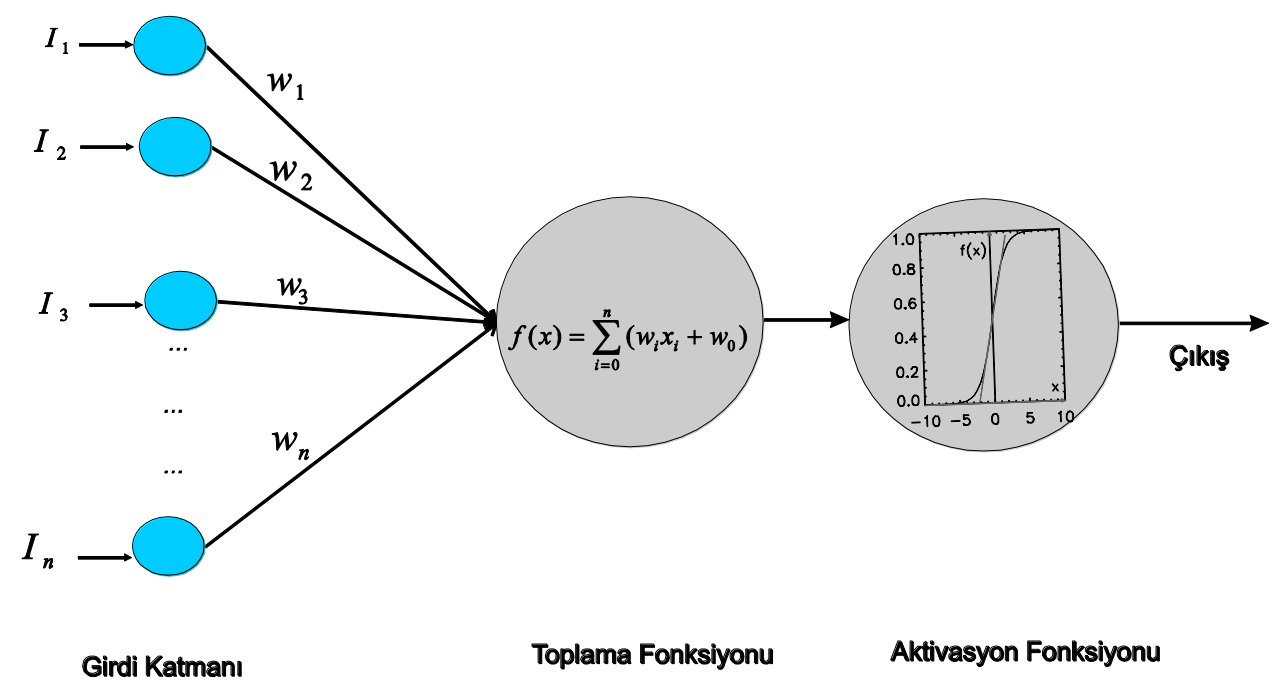

Şekil 1. Yapay sinir hücresinin genel giriş-çıkış yapısı $[5,18]$.

Her bir tabakayı birbirlerine bağlayan ileri yayılımlı (Feedforward Propagation) ya da geriye yayılımlı (Feedback propagation) olmak üzere iki tane öğrenme (training) algoritma vardır. En iyi öğrenme algoritmaların başında Levenberg-Marquardt öğrenme algoritması kullanan geri yayılımlı YSA olduğu görülmektedir. Denetimli öğrenmeyi kullanan geri yayılımlı algoritma, katmanlı ileri yayılımlı YSA'larda kullanılır. Bu, yapay nöronların katmanlar halinde organize edildiği ve sinyallerini ileri gönderildiği ve daha sonra hataların tekrar geriye doğru yayıldığı anlamına gelmesidir. Nöronlar ağın girdi katmanındaki girdileri alır ve çıktı katmanına çıktı olarak gönderirler. Geri yayılımlı algoritmasının amacı, YSA eğitim verilerini öğrenene kadar hataları azaltmaktır [3, 15, 19].

\subsection{Angström tipi eşitlikler modelleri}

Pek çok bölge için yatay bir yüzey üzerinde ölçülmüş güneş radyasyonu verilerinin eksikliğinden dolayı o bölgeye ait mevcut olan meteorolojik parametreleri (güneşlenme süresi, sıcaklık, bağıl nem, enlem, boylam gibi) kullanarak global güneş radyasyonunu tahmin etmek için literatürde çalışılmış pek çok lineer modeller geliştirilmiştir [612,20]. Literatürde, başlangıçta lineer regresyon ifadesi olarak ifade edilen AngströmPrescott-Page eşitlikleri kullanan modeller geliştirilmiştir [6, 7, 21]. Güneşlenme süresine bağlı eşitlikler için genel formülü,

$$
\frac{H}{H_{0}}=a+b\left(\frac{S}{S_{0}}\right)
$$

ile verilmektedir. Burada $H / H_{0}$ her hangi bir yatay yüzeye gelen günlük global güneş ışınımın $(H)$ atmosfer dişı (extraterrestial) 1şınıma $\left(H_{0}\right)$ oranıdır. Denklem 1'de görüldügüu gibi $H / H_{0}$ değeri saat cinsinden ölçülen güneşlenme süresine $(\mathrm{S})$ ve olas1 
maksimum gün uzunluğuna $\left(S_{0}\right)$ bağlıdır. a ve $b$ değerleri Angström katsayıları katsayılarıdır. Atmosfer dışı güneş 1şınımı $\left(H_{0}\right)$;

$$
H_{0}=\frac{24 \times 3600 \times G_{s c}}{\pi}\left[1+0.033 \cos \left(\frac{360 D}{365}\right)\right] \times\left[\cos \phi \cos \delta \sin w_{s}+\frac{\pi w_{s}}{180} \sin \phi \sin \delta\right](2)
$$

eşitliği ile hesaplanır [22-24]. Burada $\mathrm{I}_{\mathrm{sc}}$ güneş sabiti $\left(1367 \mathrm{~W} / \mathrm{m}^{2}\right), \mathrm{D}, 1$ Ocak 31 Aralık arasındaki yılın günleridir. $\phi$ ölçüm yapılan yerin enlemi $\left(^{\circ}\right), \delta$ deklinasyon açısı $\left(^{\circ}\right), \omega_{\mathrm{s}}$ güneşin batış açısı $\left(^{\circ}\right)^{\prime}$ dır. $\delta$ ve $\omega_{\mathrm{s}}$ açı değerleri sırasıyla,

$$
\begin{gathered}
\delta=23.45 \sin \left[\frac{360}{365}(284+D)\right] \\
w_{s}=\cos ^{-1}[-\tan (\delta) \tan (\phi)]
\end{gathered}
$$

denklemleriyle hesaplanır. $\omega_{\mathrm{s}}$ açısı kullanılarak aylık ortalama günlük maksimum gün uzunluğu $\left(\mathrm{S}_{0}\right)$ (saat/gün) ise

$$
S_{o}=\frac{2}{15} \cos ^{-1}[-\tan (\delta) \tan (\phi)]=\frac{2}{15} w_{s}
$$

ile hesaplanabilir [22-25]. $\mathrm{H} / \mathrm{H}_{0}$ oranı açıklık indeksi $\left(\mathrm{KT}=\mathrm{H} / \mathrm{H}_{0}\right)$ olarak da bilinmektedir. Birçok araştırmacı açıklık indeksini) ampirik korelasyonlar geliştirmek için kullanmıştır [1, 6-12, 15].

\section{3 İstatistiksel değerlendirme araçları}

Literatürde, YSA ve teorik/ampirik gibi Angström tipi modellerden hesaplanan güneş radyasyon sonuçlarının belirli yöntemler kullanılarak ölçülen verilerle kıyaslanması ve doğruluğunun test edilmesi amacıyla değişik test yöntemleri kullanılmaktadır. Bu çalışmada, farklı modelleri değerlendirmek için Korelasyon Katsayısı (Correlation Coefficent: $\mathrm{R}^{2}$ ), Hata Kareleri Ortalamasının Karekökü (Root Mean Square Error: RMSE), Mutlak Hata Oranları Ortalaması (Mean Absolute Percentage Error: MAPE) ve Hata Kareleri Ortalaması (Mean Square Error: MSE) gibi dört farklı istatistiksel hata yöntemi kullanılmıştır [26]. Bu nicel göstergeler aşağıda kısaca özetlenmiştir.

$$
\begin{gathered}
R^{2}=1-\frac{\sum_{i=1}^{n}\left(H_{i, \ddot{o}}-H_{i, h}\right)^{2}}{\sum_{i=1}^{n}\left(H_{i, \ddot{o}}-\bar{H}_{i, \ddot{o}}\right)^{2}} \\
R M S E=\sqrt{\frac{1}{n} \sum_{i=1}^{n}\left(H_{i, \ddot{o}}-H_{i, h}\right)^{2}}\left(\mathrm{MJm}^{-2} \mathrm{~g}^{-1}\right) \\
M A P E=\frac{1}{n} \sum_{i=1}^{n}\left|\frac{\left(H_{i, \ddot{o}}-H_{i, h}\right)}{H_{i, \ddot{o}}}\right| \times 100 \quad(\%) \\
M S E=\frac{1}{n} \sum_{i=1}^{n}\left(H_{i, \ddot{o}}-H_{i, h}\right)^{2} \quad\left(\mathrm{MJm}^{-2} \mathrm{~g}^{-1}\right)
\end{gathered}
$$

Burada, $H_{i, o}$ and $H_{i, h}$ sirasıyla i.inci ölçülen ve modellerden hesaplanan güneş radyasyon değerlerini göstermektedir $\left(\mathrm{MJm}^{-2} \mathrm{~g}^{-1}\right)$. Daha iyi veri modelleme sonuçları için, istatistiksel hata parametreleri sıfıra yakın olması gerekir. $\mathrm{R}^{2}$ göstergesi genellikle modellerin performansını tahmin etmek için kullanılan bir istatistiksel yöntemdir. $\mathrm{R}^{2} 0$ 
ile 1 arasında değişmekte ve bu değerin 1'e yaklaşması model tahminleri ile ölçüm değerleri arasındaki bağımlılığın kuvvetli olduğu anlamına gelmektedir. RMSE değeri ne kadar düşükse (yani sıfıra yaklaşması) mutlak sapması açısından bir modelin öngörü yeteneği o kadar iyidir. MAPE (\%) göstergesi sıfıra ne kadar yakınsa performans göstergesi o kadar yüksek olur. MSE değeri sıfıra ne kadar yaklaşırsa modelin tahmin kabiliyetinin o kadar iyi artması anlamına gelmektedir [5, 26].

\section{Bulgular}

\subsection{Yapay sinir ăğ kullanılarak güneş enerjisinin tahmin edilmesi}

Bu çalışmada, YSA modeli için MATLAB ortamında "nntool" komutu kullanılarak Gaziantep, Antakya ve Kahramanmaraş bölgeleri için aylık ortalama global güneş 1şınım şiddet verilerini tahmin edilmeye çalışılmıştır. MGM'den alınan 15 yıllık (19932007) meteorolojik ve coğrafik verilerin \%74'ü eğitim, \%13'ü doğrulama (validation) ve \%13'i ise test için kullanılmıştır. Bu verilerden doğrulama verisi olarak toplam dört yıllık (1993, 2003, 2004, 2005) ölçülen global güneş enerji verisi kullanılmıştır. Ağda, on farklı coğrafik ve meteorolojik parametre girdi olarak kullanılırken sadece bir çıktı (toplam global güneşlenme şiddeti) parametresi tahmin edilmiştir (Şekil 2). A ğın eğitilmesinde pek çok model denenmiş ve $\mathrm{R}^{2}$, RMSE, MSE, ve MAPE istatistiksel hata sonuçlarına bakılarak en uygun model bulmaya çalışılmıştır. İleri beslemeli geri yayılımlı ağ (Feed Forward Backpropagation neural network) "trainlm" eğitim algoritması kullanılarak birinci gizli katmandaki $\left(\mathrm{H}_{\mathrm{i}}\right)$ nöron sayılarını $(\mathrm{HN} 1)$ ikişer ikişer arttırarak 2-50 arasında ve ikinci gizli katmandaki nöron (HN2) sayılarını da birer birer arttırılıp 1-5 arasında aşamalı olarak değiştirilerek farklı modeller oluşturulmuş ve farklı sayıda nöronlar için ağ eğitilmiş ve test edilmiştir. Her model için $\mathrm{R}^{2}$, RMSE, MSE, ve MAPE istatistiksel hata sonuçlarına bakılmıştır. Bu çalışmada, kullanılan on tane farkl1 girdi ( $\left.\mathrm{I}_{1-10}\right)$ katmandan, iki tane gizli katmandan $\left(\mathrm{H}_{1-4} \mathrm{ve}_{1-2}\right)$ ve bir tane de çıktı $\left(\mathrm{O}_{1}\right)$ katmandan oluşan YSA'nın mimari yapısı Şekil 2'de verilmiştir. Yerleşim yerlerine ait istasyon adları, yılın ayları, yerleşim yerlerinin enlem, boylam, yükseklik, ortalama sıcaklık, bağıl nem, bulutluluk, buhar basıncı ve güneşlenme süreleri girdi katmanı ile ağa sunulmakta ve gizli katmanlardaki fonksiyonlar ile ağ eğitildikten sonra toplam global güneşlenme şiddeti sonuçları çıktı katmanında elde edilmektedir.

YSA'nın mimari yapısı, eğitim "training" veya öğrenme "learning" algoritmaları ve aktivasyon fonksiyonları ile karakterize edilmektedir. $\mathrm{Bu}$ çalışmada, YSA'nın eğitilmesinde kullanılan eğitim "training" parametreleri Tablo 1'de verilmiştir. Eğitim rastgele ağırlıklarla başlar ve hatanın minimum düzeyde olacağı şekilde ayarlamaktır.

Yapılan YSA modelleme sonucunda modellerinin iyi çalışıp çalışmadığı, ölçülen gerçek değerler ile YSA modelinin oluşturduğu çıktı değerleri arasındaki sapma miktarına bağlıdır [5]. Yukarıda belirtildiği gibi en uygun YSA'nın mimari yapısını belirlemek için $\mathrm{R}^{2}$, RMSE, MSE ve MAPE gibi dört farklı istatistiksel yöntemleri kullanılmış ve hataların karşılaştırılarak en uygun model bulunmaya çalıșılmıştır. Bu istatistiksel değerlere göre en uygun $\mathrm{R}^{2}$ (\% 99.01), RMSE $\left(0.6759 \mathrm{MJ} / \mathrm{m}^{2}\right)$, MSE $\left(0.4568 \mathrm{MJ} / \mathrm{m}^{2}\right)$ ve MAPE (\% 4.67) değerlerine sahip iki gizli katmanlı en iyi modelin birinci gizli katmanda dört nöron ve ikinci gizli katmanda iki nöron olan mimari yapının (10-4-2-1) olduğu görülmüștür (Şekil 3). 


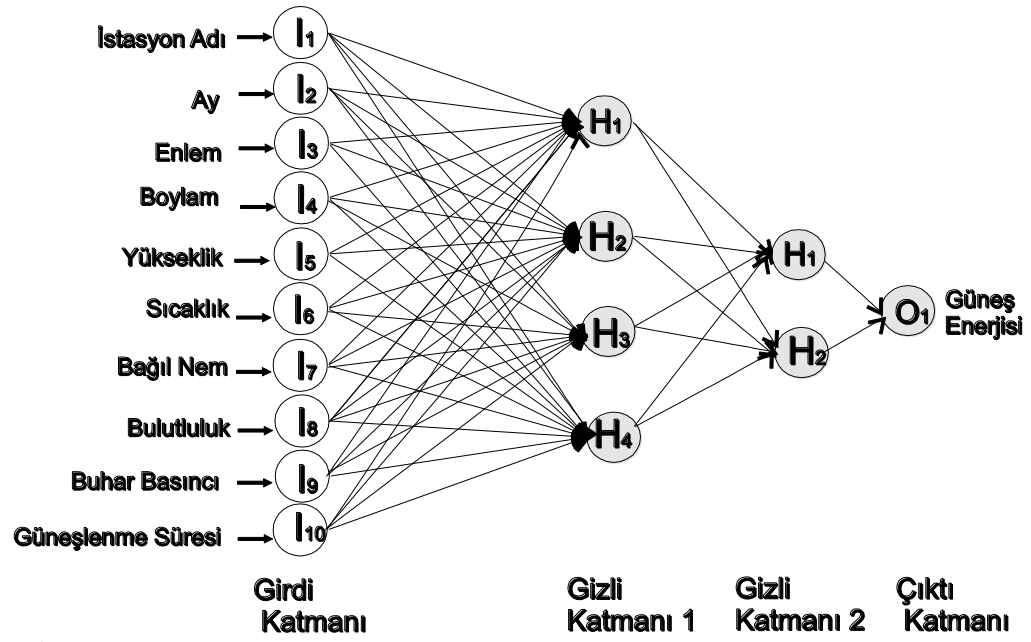

Şekil 2. İki gizli katmanda on nöron için kullanılan Yapay Sinir Ağı Mimarisi $[5,19]$.

Tablo 1. YSA'da kullanılan eğitim “training” parametreleri

\begin{tabular}{|l|l|l|l|}
\hline net.trainParam.showWindow & true & net.trainParam.mu_max & $1.00 \mathrm{E}+08$ \\
\hline net.trainParam.showCommandLine & false & net.trainParam.time & 1000 \\
\hline net.trainParam.max_fail & 6 & net.trainparam.show & 50 \\
\hline net.trainParam.min_grad & $1.00 \mathrm{E}-07$ & net.trainparam.lr & $1.00 \mathrm{E}-03$ \\
\hline net.trainParam.mu & $1.00 \mathrm{E}-03$ & net.trainparam.epochs & $1.00 \mathrm{E}+03$ \\
\hline net.trainParam.mu_dec & 0.6 & net.trainParam.time & $1.00 \mathrm{E}+03$ \\
\hline net.trainParam.mu_inc & 10 & & \\
\hline
\end{tabular}

Şekil 3'te çok katmanlı ileri yayılımlı Levenberg Marquardt algoritmasını (trainlm) kullanan yapay sinir ağ yapısının kurulan eğitim algoritması verilmiştir. Şekil 3'de görüldügü gibi girdi katmanda 10 tane girdi parametresi ağa sunulmuş ve iki tane gizli katman kullanılarak ağ eğitilmiş ve bir tane çıktı elde edilmiştir. Gizli katmanların her ikisinde de hiperbolik tanjant sigmoid (tansig) aktivasyon fonksiyonu ve her gizli katmanda sırasıyla 4 ve 2 tane gizli nöronlar kullanılmıştır. Çıktı katmanında lineer (purelin) fonksiyonu kullanılmıştır. YSA'nın performansı mse (Mean Square Error) kullanılarak test edilmiştir. Bu modelin performans çıktısına göre eğitilen ve test edilen ağ 36 iterasyonda (epoch) gradyant1 7.8732, performans1 0.487 , Mu değeri 0.0103 ve doğrulama kontrolü 6 ile en iyi doğrulama performansına ulaşmış ve iyi bir performans elde etmiştir. Verilerin doğruluğunun test edilmesinde kullanılan regrasyon değerleri eğitilen $(R=0.99342)$, validation $(R=0.99439)$ ve test edilen $(R=0.98787)$ veriler için $R$ değerleri ortalama $>0.99$ olduğu için makul derecede iyi olduğu görülmüştür [5].

Gaziantep, Antakya ve Kahramanmaraş bölgeleri için karar verilen en uygun YSA mimari yapısı (10-4-2-1) kullanılarak aylık olarak yıllık güneş ışınım şiddeti tahmin edilmiştir. Verilerin eğitimi sonucu modelden hesaplanan ve MGM'den alınan ölçülmüş gerçek güneş enerjisi değerler ile karşılaştırılması yapılmış ve sonuçlar Şekil 4 ile Şekil 5 'te verilmiştir. Modelden hesaplanan ve ölçülen toplam dört yıllık (1993, 2003, 2004, 2005) global güneş enerjisi değerleri arasındaki korelasyon $\left(\mathrm{R}^{2}\right)$ ilişkisine bakılmış ve grafiklerin sol üst köşelerinde verilmiştir (Şekil 4). Şekil 4 incelendiğinde, YSA modeli ile hesaplan ve ölçülmüş değer arasındaki korelasyon $\left(\mathrm{R}^{2}\right)$ değerleri (ve regresyon eşitlikleri) sirasıyla Gaziantep için $\mathrm{R}^{2}=0.984\left(H_{Y S A}=1.02 H_{M G M}+0.01\right)$, Antakya için $\mathrm{R}^{2}=0.992 \quad\left(H_{Y S A}=0.99 H_{M G M}+0.16\right) \quad$ ve Kahramanmaraş için $\mathrm{R}^{2}=0.993$ $\left(H_{Y S A}=1.01 H_{M G M}+0.011\right)$ olduğu görülmüştür. Bu değerlere göre YSA modelinden hesaplanan değerlerin ölçülen gerçek değerler arasında oldukça uyumlu olduğu görülmektedir. 
Şekil 5'te Gaziantep, Antakya ve Kahramanmaraş bölgeleri için YSA modeli ile hesaplanan ( $\left.\mathrm{H}_{\mathrm{YSA}}\right)$ ve test amaciyla ölçülen $\left(\mathrm{H}_{\mathrm{MGM}}\right)$ dört yıllık $(1993,2003,2004,2005)$ verilerin aylara göre değişimleri $\mathrm{MJm}^{-2} \mathrm{~g}^{-1}$ biriminde verilmiştir. $\mathrm{H}_{\mathrm{MGM}}$ değerler içi dolu çemberle ve mavi renkle gösterilirken $\mathrm{H}_{\text {YSA }}$ değerler ise içi boş çemberle ve kırmızı renkle gösterilmiştir.

Şekil 5'te verilen $\mathrm{H}_{Y S A}$ ve $\mathrm{H}_{\text {MGM }}$ verilerinin dört yıllık (1993, 2003, 2004, 2005) global güneş enerjisi verilerinin ortalamaları alınmış ve yıllık olarak aylara göre ortalamaları değişimleri elde edilmiş ve sonuçlar Tablo 2'de verilmiştir. Tablo 2 incelendiğinde hesaplanan ve ölçülen değer arasında Gaziantep bölgesi için $\mathrm{R}^{2}=0.994$, Antakya bölgesi için $\mathrm{R}^{2}=0.997$ ve Kahramanmaraş bölgesi için $\mathrm{R}^{2}=0.998$ olduğu görülmüş ve bu değerlere göre ölçülen ve hesaplanan değerlerin bir birleriyle oldukça uyumlu olduğu görülmüştür. Tablo 2'de verilen hesaplanmış ve ölçülmüş veriler kullanılarak aylara göre değişim grafiği Şekil 6'da verilmiştir. Yukarıda belirtildiği gibi, Şekil 6'da her üç bölge için ölçülen $\left(\mathrm{H}_{\mathrm{MGM}}\right)$ değerler içi dolu çemberle ve mavi renkle gösterilirken, YSA modelinden hesaplanan (HYSA) değerler içi boş çemberle ve kırmızı renkle gösterilmiştir. Böylece, Tablo 2'den ve Şekil 6'dan görüldüğü gibi Levenberg Marquardt algoritmalı (trainlm) iki gizli katmanlı mimari yapıyla (10-4-2-1) hesaplanmış değerlerin ölçülen değerlere oldukça uyumlu olduğu görülmüştür.

\subsection{Angström- Prescot tipi lineer eşitlikler kullanılarak güneş enerjisinin tahmin edilesi}

Angström-Prescott-Page eşitliği (Denklem 1) kullanılarak Gaziantep, Antakya ve Kahramanmaraş bölgeleri için aylık olarak yıllık güneş ışınım şiddetleri tahmin etmek için bir dizi model (M1-M5) geliştirilmiştir. Modellerin geliştirilmesinde MGM'den alınan 1993-2007 (15 yıl) yılları arasındaki meteorolojik ve coğrafik verilerin aylık ortalama değerleri kullanılmıştır. Bunlar sırasıyla ortalama güneşlenme süresine (S) ve gün uzunluğuna $\left(\mathrm{S}_{\mathrm{o}}\right)$, ortalama sicaklık $(\mathrm{T})$ ve bağıl nem $(\mathrm{BN})$ gibi coğrafik ve meteorolojik parametreler ile Denklem 3 'den hesaplanan deklinasyon açısı $(\delta)$ olarak sıralanabilir. Geliştirilen modeller Tablo 3'de verilmiştir. Tablo 3'de birinci sütunda M1-M5 arasinda modellerin isimleri $\left(\mathrm{H}_{\mathrm{M} 1}-\mathrm{H}_{\mathrm{M}}\right)$, ikinci sütunda belirli parametrelere bağlı olarak geliştirilen eşitlikler ve son üç sütunda ise sırasıyla Gaziantep, Antakya ve Kahramanmaraş bölgeleri için eşitliklerde kullanılan sabit değerler verilmiştir. Tablo 3 incelendiğinde, $\mathrm{M} 1, \mathrm{M} 2$ ve M3 modelleri sırasıyla $\mathrm{S} / \mathrm{S}_{0}$ oranına bağlı lineer (doğrusal), ikinci dereceden (kuadratik) ve üçüncü dereceden (kübik) regresyonlardan oluşmaktadır. M4 modeli, lineer $\mathrm{S} / \mathrm{S}_{0}$ oranına ve deklinasyon açısına $(\delta)$ ve ortalama sıcaklığa $(\mathrm{T})$ ve $\mathrm{M} 5$ modeli ise lineer $\mathrm{S} / \mathrm{S}_{0}$ oranına ve bağıl neme $(\mathrm{BN})$ bağlıdır. 

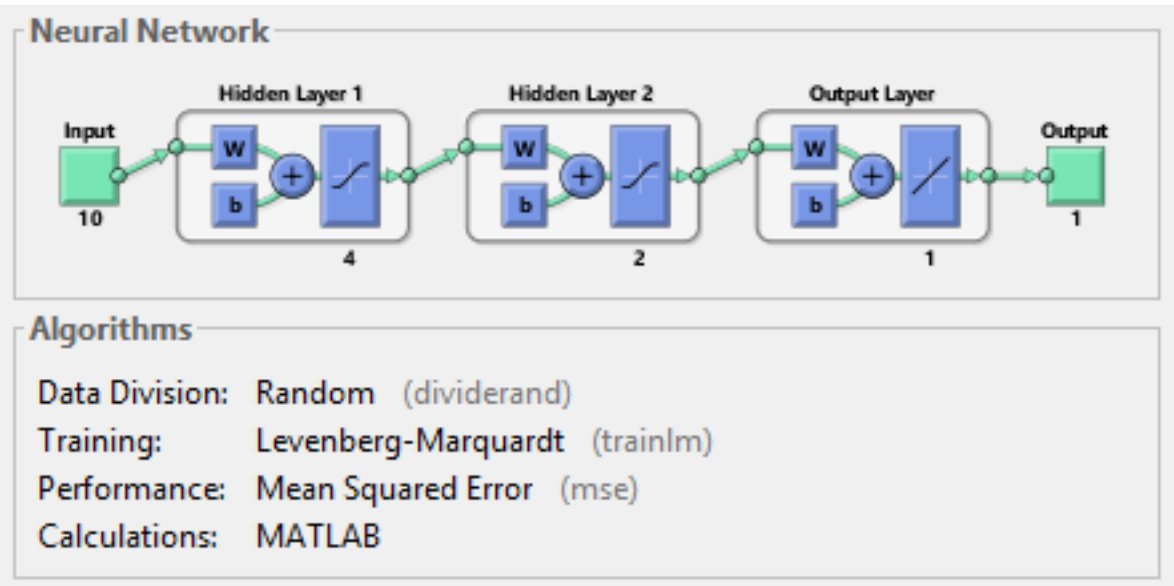

\begin{tabular}{|c|c|c|c|}
\hline \multicolumn{4}{|l|}{ Progress } \\
\hline Epoch: & 0 & 36 iterations & 1000 \\
\hline Time: & $0: 00: 00$ & $0: 00: 00$ & $0: 16: 40$ \\
\hline Performance: & 64.4 & 0.487 & 0.00 \\
\hline Gradient: & 102 & 7.87 & $1.00 \mathrm{e}-07$ \\
\hline Mu: & 0.00100 & 0.0103 & $1.00 \mathrm{e}+08$ \\
\hline Validation Checks: & 0 & 6 & 6 \\
\hline
\end{tabular}

Şekil 3. Kurulan çok katmanlı YSA yapısı
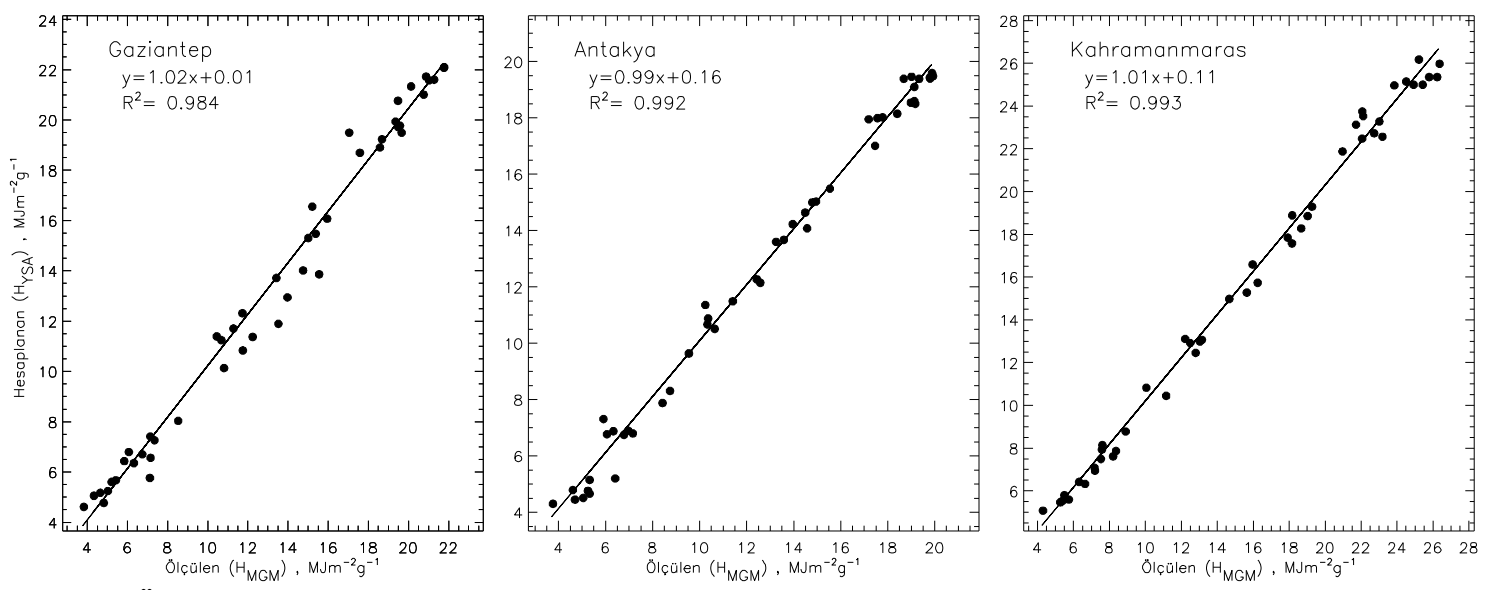

Şekil 4. Üç bölge YSA ile tahmine edilen ve gerçek meteorolojik değerleri arasındaki korelasyon ilişkisi
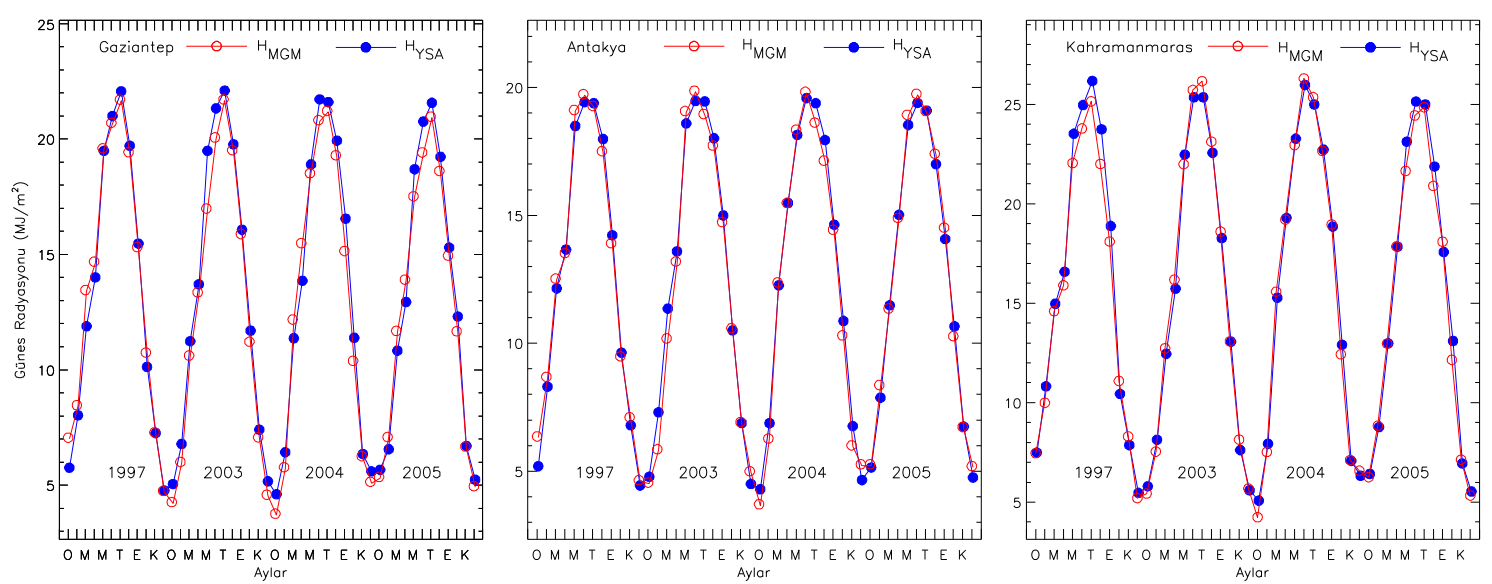

Şekil 5. YSA ile tahmine edilen ve gerçek meteorolojik değerlerin dört yıllık karşılaştırılması 
Tablo 2. YSA ile tahmine edilen ve gerçek meteorolojik değerlerin yıllık değişimlerin aylara göre yıllık

\begin{tabular}{|c|c|c|c|c|c|c|}
\hline \multirow{2}{*}{ Aylar } & \multicolumn{2}{|c|}{ Gaziantep } & \multicolumn{2}{|c|}{ Antakya } & \multicolumn{2}{|c|}{ Kahramanmaraş } \\
\hline & $\mathbf{H}_{\mathrm{YSA}}$ & $\mathbf{H}_{\text {MGM }}$ & $\mathbf{H}_{\mathrm{YSA}}$ & $\mathbf{H}_{\text {MGM }}$ & $\mathbf{H}_{\mathbf{Y S A}}$ & $\mathbf{H}_{\mathrm{MGM}}$ \\
\hline Oca & 5.32 & 5.12 & 4.9 & 4.98 & 6.25 & 5.84 \\
\hline Şub & 7 & 6.84 & 7.63 & 7.3 & 8.97 & 8.47 \\
\hline Mar & 11.38 & 11.99 & 11.86 & 11.61 & 13.98 & 13.97 \\
\hline Nis & 13.68 & 14.36 & 14.48 & 14.28 & 17.42 & 17.29 \\
\hline May & 19.19 & 18.16 & 18.49 & 18.87 & 23.16 & 22.16 \\
\hline Haz & 21.25 & 20.25 & 19.51 & 19.8 & 25.41 & 25.06 \\
\hline Tem & 21.88 & 21.41 & 19.38 & 18.99 & 25.43 & 25.38 \\
\hline Ăgu & 19.71 & 19.22 & 17.78 & 17.45 & 22.78 & 22.17 \\
\hline Eyl & 15.9 & 15.33 & 14.53 & 14.4 & 18.45 & 18.44 \\
\hline Eki & 11.43 & 11.01 & 10.46 & 10.17 & 12.44 & 12.19 \\
\hline Kas & 6.98 & 6.83 & 6.84 & 6.69 & 7.43 & 7.67 \\
\hline Ara & 5.24 & 4.87 & 4.63 & 5.03 & 5.78 & 5.69 \\
\hline
\end{tabular}
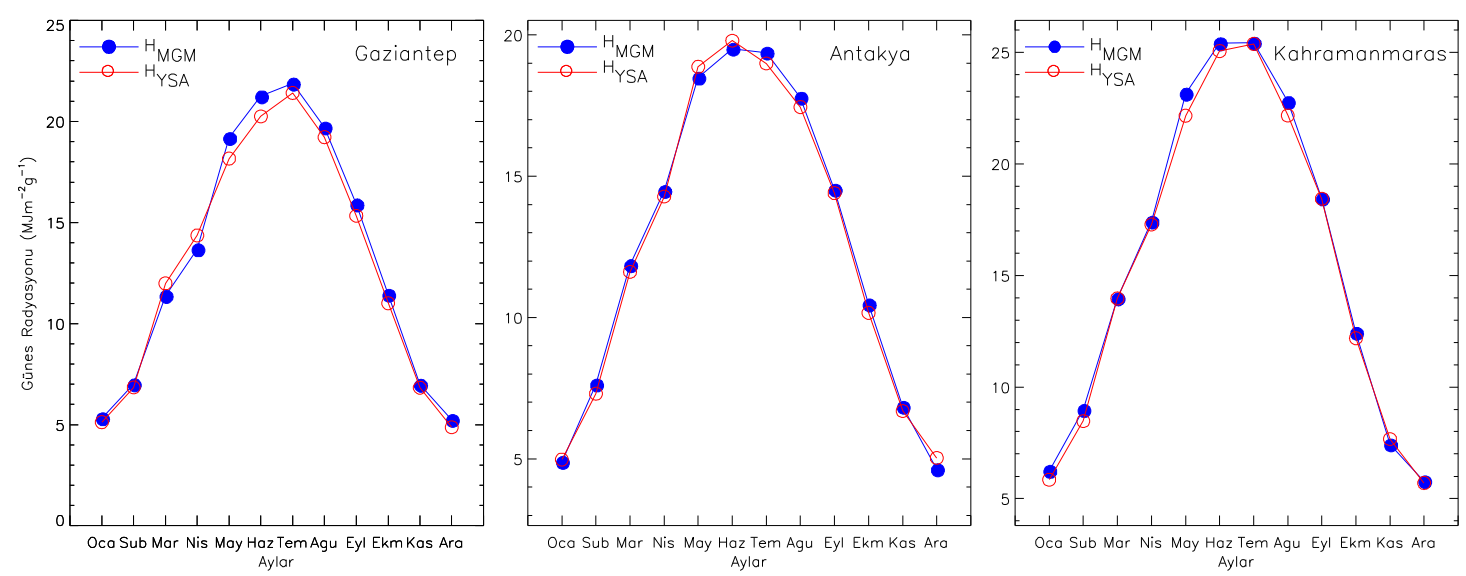

Şekil 6. YSA ile tahmine edilen ve gerçek meteorolojik değerlerin yıllık değişimlerin aylara göre yıllık ortalamalar1

MGM'nün web sayfasından alınan 1940-2020 yılları arasındaki periyotlarının ortalaması olan aylık güneşlenme süresi (S) kullanılarak Denklem 2'den hesaplanan atmosfer dışı 1şınım $\left(\mathrm{H}_{0}\right)$, Denklem 4'den hesaplanan güneşin batış açısı $\left(\omega_{\mathrm{s}}\right)$ ve Denklem 5'den hesaplanan aylık ortalama günlük maksimum gün uzunluğu $\left(\mathrm{S}_{0}\right)$ değerleri Gaziantep, Antakya ve Kahramanmaraş bölgeleri için hesaplanmış ve sonuçlar Tablo 4'de verilmiştir. Tablo 4'de son iki sütunda ise MGM'den alınan ve YSA modelinde de kullanılan 1993-2007 (15 yıl) yılları arasındaki aylık ortalama sicaklık (T) ve bağıl nem $(\mathrm{BN})$ değerleri de verilmiştir. Tablo 4'deki değerler kullanılarak Tablo 3 'de verilen modellerin $\left(\mathrm{H}_{\mathrm{M} 1}-\mathrm{H}_{\mathrm{M} 5}\right)$ katsayıları belirlenmiş ve her üç bölge için yatay yüzeye gelen aylık olarak ortalama güneş 1şınımın değerlerin hesaplanması sağlanmıştır.

Modellerin geliştirilmesinde MGM'den alınan ve Tablo 2'de verilen YSA modelinde test amacıyla kullanılan dört yıllık (1993, 2003, 2004, 2005) ölçülmüş verilerin ortalama değerleri $\left(\mathrm{H}_{\mathrm{MGM}}\right)$ kullanılmıştır. Geliştirilen modellerden $\left(\mathrm{H}_{\mathrm{M} 1}-\mathrm{H}_{\mathrm{M} 5}\right)$ hesaplanan aylık olarak ortalama güneş ışınımın değerlerin doğruluk performansını görmek amaciyla $\mathrm{R}^{2}$, RMSE, MAPE ve MSE istatistiksel hata yöntemleri (Denklemler 
6-9) kullanılmıştır. Daha iyi veri modellemesi için $\mathrm{R}^{2}$ mümkün olduğunca 1'e ve RMSE, MAPE ve MSE istatistiksel göstergelerin mutlak değerleri ise sıfıra yaklaşmalıdır. Böylece, Gaziantep, Antakya ve Kahramanmaraş bölgeleri için en ideal modeller $\left(\mathrm{H}_{\mathrm{M} 1^{-}}\right.$ $\mathrm{H}_{\mathrm{M} 5}$ ) oluştururken Tablo 3'deki verilen en uygun katsayıları belirlenirken bu istatistiksel hata değerlerini (özellikle $\mathrm{R}^{2}$ ) bakılmıştır. Ölçülen güneş 1 şınım şiddetine en yakın olacak şekilde katsayılar değiştirerek modellerden hesaplanan değerler belirlenmiştir. Gaziantep, Antakya ve Kahramanmaraş bölgeleri için $\mathrm{H}_{\mathrm{M} 1}-\mathrm{H}_{\mathrm{M} 5}$ modellerinden elde edilen aylık ortalama güneş 1şınımın değerleri için $\mathrm{R}^{2}$, RMSE, MSE ve MAPE

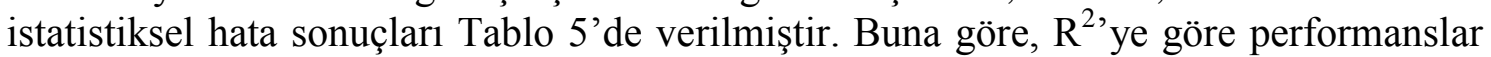
değerleri Gaziantep bölgesi için en düşük M1 için 0.990 ve en yükssek M3 için 0.993 (ort. 0.991), Antakya bölgesi için en düşük M4 için 0.980 ve en yüksek M5 için 0.992 (ort. 0.983) ve Kahramanmaraş bölgesi için en düşük M1 için 0.990 ve en yüksek M3 için 0.994 (ort. 0.992) arasında değişmektedir. Sonuçlardan görüldüğü gibi tüm değerler ortalama olarak yaklaşık 0.990 olduğundan bölgeler için geliştirilen modeller başarılı ile gerçekleştiği görülmüştür.

Tablo 3. Angström-Prescott eşitliği kullanılarak geliştirilen beş farklı model için $\mathrm{H} / \mathrm{H}_{0}$ formülleri

\begin{tabular}{|c|c|c|c|c|}
\hline \multirow[t]{2}{*}{ Model } & \multirow[t]{2}{*}{ Eşitlikler } & \multicolumn{3}{|c|}{ Katsayılar } \\
\hline & & Gaziantep & Antakya & Kahramanmaraş \\
\hline \multirow{2}{*}{$\mathbf{H}_{\mathrm{M} 1}$} & $a+b(S / S o)$ & $a=0.23172$ & $a=0.176$ & $a=0.258$ \\
\hline & & $b=0.3483$ & $b=0.382$ & $b=0.470$ \\
\hline \multirow[t]{3}{*}{$\mathrm{H}_{\mathrm{M} 2}$} & $a+b(\mathrm{~S} / \mathrm{So})+c(\mathrm{~S} / \mathrm{So})^{2}$ & $a=0.15$ & $a=0.229$ & $a=0.192$ \\
\hline & & $b=0.62$ & $b=0.454$ & $b=0.686$ \\
\hline & & $c=-0.23$ & $c=-0.212$ & $c=-0.18$ \\
\hline \multirow[t]{4}{*}{$\mathbf{H}_{\mathrm{M} 3}$} & $a+b(\mathrm{~S} / \mathrm{So})+c(\mathrm{~S} / \mathrm{So})^{2}+d(\mathrm{~S} / \mathrm{So})^{3}$ & $a=0.05$ & $a=0.12$ & $a=0.13$ \\
\hline & & $b=0.753$ & $b=0.58$ & $b=0.77$ \\
\hline & & $c=0.0045$ & $c=-0.0024$ & $c=-0.0038$ \\
\hline & & $d=-0.29$ & $d=-0.21$ & $d=-0.25$ \\
\hline \multirow[t]{4}{*}{$\mathbf{H}_{\mathrm{M} 4}$} & $a+b(S / S o)+d \operatorname{Sin} \delta+e T$ & $a=0.33$ & $a=0.299$ & $a=0.43$ \\
\hline & & $b=0.56$ & $b=0.522$ & $b=0.57$ \\
\hline & & $d=0.55$ & $d=0.453$ & $d=0.54$ \\
\hline & & $e=-1.5 \times 10^{-3}$ & $e=-1.75 \times 10^{-3}$ & $e=1.4 \times 10^{-3}$ \\
\hline \multirow[t]{3}{*}{$\mathbf{H}_{\mathbf{M} 5}$} & $a+b(S / S o)+f B N$ & $a=0.472$ & $a=0.740$ & $a=0.376$ \\
\hline & & $b=0.256$ & $b=0.156$ & $b=0.4214$ \\
\hline & & $f=0.0032$ & $f=0.0072$ & $f=-0.0015$ \\
\hline
\end{tabular}

Tablo 4. Gaziantep, Antakya ve Kahramanmaraş bölgelerine ait meteorolojik değerler.

\begin{tabular}{|c|c|c|c|c|c|c|c|c|c|c|c|c|c|c|c|c|c|c|}
\hline $\mathbf{A Y}$ & \multicolumn{6}{|c|}{ Gaziantep } & \multicolumn{6}{|c|}{ Antakya } & \multicolumn{6}{|c|}{ Kahramanmaraș } \\
\hline 1 & 3.60 & 16.23 & 73.22 & 9.76 & 4.07 & 74.01 & 3.60 & 16.23 & 73.22 & 9.76 & 4.07 & 74.01 & 3.40 & 16.06 & 73.04 & 9.74 & 4.07 & 74.01 \\
\hline 2 & 4.40 & 21.19 & 80.00 & 10.67 & 4.39 & 64.76 & 4.40 & 21.19 & 80.00 & 10.67 & 4.39 & 64.76 & 4.20 & 21.03 & 79.89 & 10.65 & 4.39 & 64.76 \\
\hline 3 & 5.60 & 28.62 & 88.17 & 11.76 & 8.81 & 66.86 & 5.60 & 28.62 & 88.17 & 11.76 & 8.81 & 66.86 & 5.50 & 28.50 & 88.15 & 11.75 & 8.81 & 66.86 \\
\hline 6 & 10.50 & 41.71 & 108.78 & 14.50 & 23.96 & 50.25 & 10.50 & 41.71 & 108.78 & 14.50 & 23.96 & 50.25 & 10.00 & 41.73 & 108.98 & 14.53 & 23.96 & 50.25 \\
\hline 7 & 10.80 & 43.25 & 107.02 & 14.27 & 28.69 & 49.78 & 10.80 & 43.25 & 107.02 & 14.27 & 28.69 & 49.78 & 10.50 & 43.25 & 107.20 & 14.29 & 28.69 & 49.78 \\
\hline 8 & 10.20 & 38.25 & 100.41 & 13.39 & 28.37 & 54.18 & 10.20 & 38.25 & 100.41 & 13.39 & 28.37 & 54.18 & 9.80 & 38.20 & 100.52 & 13.40 & 28.37 & 54.18 \\
\hline 9 & 8.90 & 30.33 & 91.68 & 12.22 & 22.93 & 55.52 & 8.90 & 30.33 & 91.68 & 12.22 & 22.93 & 55.52 & 8.70 & 30.23 & 91.69 & 12.23 & 22.93 & 55.52 \\
\hline
\end{tabular}


Tablo 5. Gaziantep, Antakya ve Kahramanmaraş bölgeleri için istatistiksel parametreler

\begin{tabular}{lllll|lllll|llll}
\hline \multicolumn{4}{c}{ Gaziantep } & \multicolumn{4}{c}{ Kahramanmaraş } \\
\hline & $\mathbf{R}^{\mathbf{2}}$ & $\mathbf{R M S E}$ & MAPE & MSE & $\mathbf{R}^{\mathbf{2}}$ & RMSE & MAPE & MSE & $\mathbf{R}^{\mathbf{2}}$ & RMSE & MAPE & MSE \\
\hline $\mathrm{H}_{\mathrm{YSA}}$ & 0.990 & 0.586 & 4.105 & 0.343 & 0.997 & 0.287 & 2.584 & 0.083 & 0.997 & 0.414 & 2.445 & 0.171 \\
$\mathrm{H}_{\mathrm{M} 1}$ & 0.990 & 0.581 & 6.072 & 0.337 & 0.982 & 0.715 & 3.618 & 0.511 & 0.990 & 0.696 & 6.161 & 0.484 \\
$\mathrm{H}_{\mathrm{M} 2}$ & 0.990 & 0.569 & 5.648 & 0.323 & 0.981 & 0.742 & 7.528 & 0.55 & 0.992 & 0.626 & 5.376 & 0.391 \\
$\mathbf{H}_{\mathbf{M} 3}$ & $\mathbf{0 . 9 9 3}$ & $\mathbf{0 . 4 8}$ & 3.229 & $\mathbf{0 . 2 3 1}$ & 0.981 & 0.75 & 6.636 & 0.563 & $\mathbf{0 . 9 9 4}$ & $\mathbf{0 . 5 6 4}$ & 4.037 & $\mathbf{0 . 3 1 8}$ \\
$\mathbf{H}_{\mathbf{M} 4}$ & 0.991 & 0.538 & $\mathbf{0 . 0 3 4}$ & 0.29 & 0.980 & 0.76 & $\mathbf{0 . 0 3 7}$ & 0.577 & 0.992 & 0.64 & $\mathbf{0 . 0 5 5}$ & 0.409 \\
$\mathbf{H}_{\mathbf{M} 5}$ & 0.99 & 0.581 & 4.827 & 0.338 & $\mathbf{0 . 9 9 2}$ & $\mathbf{0 . 4 6 8}$ & 2.939 & $\mathbf{0 . 2 1 9}$ & 0.991 & 0.665 & 5.594 & 0.442 \\
\hline
\end{tabular}

Tablo 5'de verilen $\mathrm{R}^{2}$, RMSE ve MSE istatistiksel hata sonuçlarına göre Gaziantep $\left(\mathrm{R}^{2}=0.993\right.$, RMSE $=0.480 \mathrm{MJm}^{-2} \mathrm{~g}^{-1}$ ve $\left.\mathrm{MSE}=0.231 \mathrm{MJm}^{-2} \mathrm{~g}^{-1}\right)$ ve Kahramanmaraş $\left(\mathrm{R}^{2}=0.994\right.$, $\mathrm{RMSE}=0.564 \mathrm{MJm}^{-2} \mathrm{~g}^{-1}$ ve $\left.\mathrm{MSE}=0.318 \mathrm{MJm}^{-2} \mathrm{~g}^{-1}\right)$ bölgeleri için en iyi sonucu veren modelin $\mathrm{H}_{\mathrm{M} 3}$ olduğu görülürken, Antakya $\left(\mathrm{R}^{2}=0.992, \mathrm{RMSE}=0.486 \mathrm{MJm}^{-}\right.$ ${ }^{2} \mathrm{~g}^{-1}$ ve $\mathrm{MSE}=0.219 \mathrm{MJm}^{-2} \mathrm{~g}^{-1}$ ) bölgesi için en iyi sonucu veren modelin $\mathrm{H}_{\mathrm{M} 5}$ olduğu görülmektedir. MAPE istatistiksel hata sonuçlarına bakıldığında ise her üç bölge için de

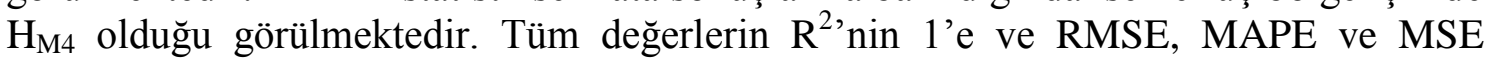
değerlerinin de 0'a yakın olmaları hem YSA modelinden hem de geliştirilen modellerden $\left(\mathrm{H}_{\mathrm{M} 1}-\mathrm{H}_{\mathrm{M} 5}\right)$ hesaplanan güneş 1şınım şiddet değerleri ile gerçek değerleri arasında bir uyum olduğunu göstermektedir.

Tablo 5'de, $\mathrm{H}_{\mathrm{M} 1}-\mathrm{H}_{\mathrm{M} 5}$ modelleri için belirlenen istatiksel hata değerlerine ek olarak YSA modelinden hesaplan $\mathrm{H}_{Y S A}$ değerleri için de istatistiksel hata sonuçları verilmiştir. Gaziantep, Antakya ve Kahramanmaraş bölgeleri için YSA modelinden tahmin edilen aylık ortalama güneş 1şınımın değerleri incelendiğinde $\mathrm{R}^{2}$ performanslar değerlerinin 0.990 ve üzeri olduğu görülmektedir. RMSE ve MSE değerleri Gaziantep için sirasıyla $0.586 \mathrm{MJm}^{-2} \mathrm{~g}^{-1}$ ve $0.343 \mathrm{MJm}^{-2} \mathrm{~g}^{-1}$ olduğu, Antakya bölgesi için $0.28 \mathrm{MJm}^{-2} \mathrm{~g}^{-1}$ ve 0.083 $\mathrm{MJm}^{-2} \mathrm{~g}^{-1}$ ve Kahramanmaraş bölgesi için $0.414 \mathrm{MJm}^{-2} \mathrm{~g}^{-1}$ ve $0.171 \mathrm{MJm}^{-2} \mathrm{~g}^{-1}$ olduğu görülmektedir. Bu bölgeler için geliştirilen YSA'dan geliştirilen modelin başarılı ile gerçekleştiği görülmüştür. İstatistiksel hata sonuçlarından incelenen bölgeler için YSA modelinin başarılı ile gerçekleştiği görülmüştür.

Gaziantep, Antakya ve Kahramanmaraş bölgeleri için MGM'den alınan ölçülmüş ortalama güneş 1şınımın değerleri $\left(\mathrm{H}_{\mathrm{MGM}}\right)$ kullanılarak YSA modelinden $\left(\mathrm{H}_{\mathrm{YSA}}\right)$ ve Angström-Prescott-Page eşitliklerinden $\left(\mathrm{H}_{\mathrm{M} 1}-\mathrm{H}_{\mathrm{M} 5}\right)$ hesaplanan aylık olarak ortalama güneş 1şınım değerlerinin aylara göre değişimi $\left(\mathrm{MJm}^{-2} \mathrm{~g}^{-1}\right)$ Tablo 6 'de verilmiştir. Tablo 6'da verilen ölçülmüş ve YSA modelinden $\left(\mathrm{H}_{\mathrm{YSA}}\right)$ ve Tablo 3'de verilen AngströmPrescott ampirik formülleri kullanılarak geliştirilen beş farklı modelden $\left(\mathrm{H}_{\mathrm{M} 1}-\mathrm{H}_{\mathrm{M} 5}\right)$ tahmin edilen aylık ortalama global güneş radyasyon değişimlerinin grafiksel olarak değişimleri Şekil 7'de verilmiştir. Tablo 5'de verilen istatistiksel parametreler incelendiğinde Gaziantep ve Kahramanmaraş için $\mathrm{R}^{2}$ değerleri 0.99'dan büyük ve Antakya için de 0.98 'dan büyük olduğu için modellerden hesaplanan $\left(\mathrm{H}_{Y S A}, \mathrm{H}_{\mathrm{M} 1}-\mathrm{H}_{\mathrm{M} 5}\right)$ güneş ışııımın aylık değişimlerinin ve MGM'den elde edilen alınan ölçülmüş $\left(\mathrm{H}_{\mathrm{MGM}}\right)$ güneş 1şınımları ile uyum içinde olduğu görülmektedir.

Tablo 6'da verilen Gaziantep, Antakya ve Kahramanmaraş bölgeleri için ölçülen $\left(\mathrm{H}_{\mathrm{MGM}}\right)$ ve YSA modelinden $\left(\mathrm{H}_{\mathrm{YSA}}\right)$ ile Angström-Prescott-Page eşitliklerinden $\left(\mathrm{H}_{\mathrm{M} 1^{-}}\right.$ $\mathrm{H}_{\mathrm{M} 5}$ ) hesaplanan aylık olarak ortalama güneş 1şınımın değerleri Denklem 2 kullanılarak hesaplanan atmosfer dışı güneş ışınımına $\left(H_{0}\right)$ oranı kullanılarak ölçülen ve hesaplanan açıklık indeksleri $\left(K_{T}=\mathrm{H} / H_{0}\right)$ hesaplanmıştır [23,24]. Elde edilen açıklık indeks $\left(K_{T}\right)$ sonuçları Tablo 7'de verilmiştir. 
Tablo 6. Ölçülen ve YSA ve ampirik eşitliklerden geliştirilen modellerden hesaplanan güneş radyasyonu verilerinin aylara göre değişimi $\left(\mathrm{MJm}^{-2} \mathrm{~g}^{-1}\right)$

\begin{tabular}{|c|c|c|c|c|c|c|c|c|c|c|c|c|}
\hline \multicolumn{13}{|c|}{ Gaziantep } \\
\hline & Oca & Şub & Mar & Nis & May & Haz & Tem & Ăgu & Eyl & Eki & Kas & Ara \\
\hline $\boldsymbol{H}_{M G M}$ & 5.12 & 6.84 & 11.99 & 14.36 & 18.16 & 20.25 & 21.41 & 19.22 & 15.33 & 11.01 & 5.83 & 4.87 \\
\hline$H_{Y S A}$ & 5.32 & 7.00 & 11.38 & 13.68 & 19.19 & 21.25 & 21.89 & 19.71 & 15.90 & 11.43 & 6.98 & 5.24 \\
\hline$H_{M 1}$ & 5.85 & 7.96 & 11.38 & 14.48 & 18.41 & 20.18 & 21.43 & 19.01 & 14.72 & 10.99 & 7.69 & 5.68 \\
\hline$H_{M 2}$ & 5.64 & 7.77 & 11.25 & 14.40 & 18.35 & 19.95 & 21.09 & 18.70 & 14.54 & 10.93 & 7.65 & 5.49 \\
\hline $\boldsymbol{H}_{M 3}$ & 5.07 & 7.20 & 10.77 & 14.13 & 18.33 & 20.14 & 21.27 & 18.85 & 14.68 & 10.98 & 7.50 & 4.98 \\
\hline $\boldsymbol{H}_{M 4}$ & 5.12 & 7.19 & 10.53 & 13.71 & 17.76 & 20.20 & 21.43 & 19.08 & 14.80 & 10.82 & 7.37 & 4.98 \\
\hline$H_{M 5}$ & 5.35 & 7.85 & 10.87 & 4.07 & 7.94 & 20.71 & 21.91 & 18.88 & 14.58 & 10.46 & 7.15 & 5.12 \\
\hline \multicolumn{13}{|c|}{ Antakya } \\
\hline & Oca & Şub & Mar & Nis & May & Haz & Tem & Ăgu & Eyl & Eki & Kas & Ara \\
\hline$H_{M G M}$ & 4.98 & 7.30 & 11 & 14.28 & 18.87 & 19.80 & 18.99 & 17.45 & 14. & 10. & 6.69 & 5.03 \\
\hline $\boldsymbol{H}_{Y S A}$ & 4.90 & 7.63 & 11.86 & 14.49 & 18.49 & 19.51 & 19.38 & 17.78 & 14.53 & 10.47 & 6.84 & 4.63 \\
\hline$H_{M 1}$ & 5.09 & 7.29 & 10 & 13. & 17.60 & 15 & 20.53 & 1 & 1 & 10.26 & 6.83 & 5.17 \\
\hline $\boldsymbol{H}_{M 2}$ & 5.99 & 8.28 & 11.76 & 14.55 & 17.99 & 18.72 & 19.65 & 17.43 & 13.81 & 10.60 & 7.54 & 5.98 \\
\hline$H_{M 3}$ & 5.13 & 7.53 & 1 & 14.28 & 18.17 & 19.30 & 20.40 & 18.09 & 14.27 & 10.63 & 7.12 & 5.28 \\
\hline$H_{M 4}$ & 4.81 & 7.13 & 10.71 & 13.65 & 17.62 & 19.33 & 20.73 & 18.35 & 14.42 & 10.26 & 6.71 & 4.95 \\
\hline$H_{M 5}$ & 4.80 & 7.38 & 11.23 & 13.93 & 8.12 & 19.98 & 20.15 & 17.22 & 14.39 & 10.59 & .63 & 4.66 \\
\hline \multicolumn{13}{|c|}{ Kahramanmaraş } \\
\hline & Oca & Şub & Mar & Nis & May & Haz & Tem & A $\breve{g} \mathbf{u}$ & Eyl & Eki & Kas & Ara \\
\hline$H_{M G M}$ & 5.85 & 8.47 & 13.97 & 17.29 & 22.16 & 25.06 & 25.38 & 22.17 & 18.44 & 12.19 & 7.67 & 5.69 \\
\hline $\boldsymbol{H}_{Y S A}$ & 6.25 & 8.98 & 13.98 & 17.42 & 23.16 & 25.41 & 25.43 & 22.78 & 18.45 & 12.44 & 7.43 & 5.78 \\
\hline$H_{M 1}$ & 6.78 & 9.32 & 13.62 & 17.24 & 21.86 & 24.26 & 26.10 & 22.98 & 17.92 & 12.92 & 8.53 & 6.50 \\
\hline $\boldsymbol{H}_{M 2}$ & 6.58 & 9.14 & 13.50 & 17.16 & 21.81 & 24.15 & 25.91 & 22.82 & 17.81 & 12.89 & 8.43 & 6.31 \\
\hline$H_{M 3}$ & 6.23 & 8.78 & 13.22 & 16.95 & 21.69 & 24.06 & 25.72 & 22.66 & 17.72 & 12.84 & 8.23 & 5.97 \\
\hline$H_{M 4}$ & 6.61 & 9.19 & 13.48 & 17.04 & 21.51 & 24.08 & 25.84 & 22.75 & 17.91 & 12.82 & 8.38 & 6.32 \\
\hline$H_{M 5}$ & 6.62 & 9.36 & 13.48 & 17.18 & 21.80 & 24.64 & 26.43 & 23.03 & 17.92 & 12.77 & 8.40 & 6.32 \\
\hline
\end{tabular}
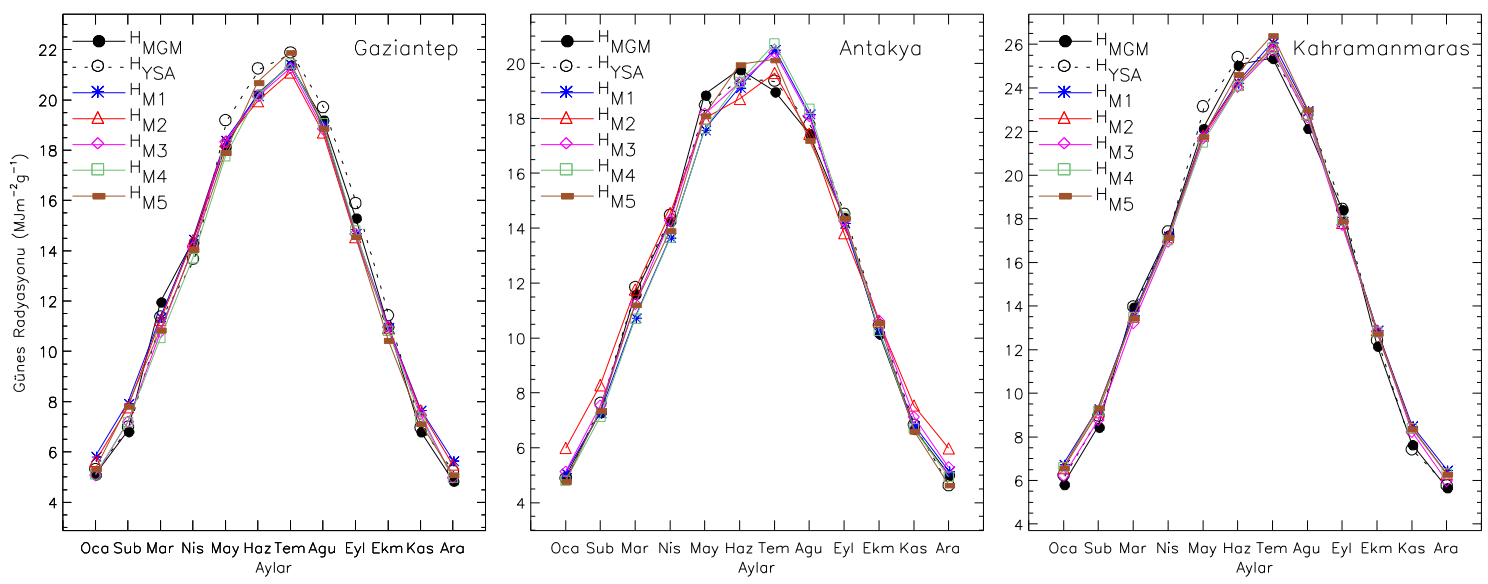

Şekil 7. YSA modelinden $\left(\mathrm{H}_{\mathrm{YSA}}\right)$ ve ampirik eşitliklerden geliştirilen beş farklı modelden $\left(\mathrm{H}_{\mathrm{M} 1}-\mathrm{H}_{\mathrm{M} 5}\right)$ tahmin edilen değerlerin ölçüm sonuçlarıyla aylara göre karşılaştırılması

Tablo 7'de verilen açıklık indeksinin ölçülen ve modellerden tahmin edilen aylık ortalama değişimlerinin grafiği Şekil 8'de verilmiştir. Gaziantep bölgesi için açıklık 
indeks değerlerinin minimum ve maksimum değerleri sırasıyla ölçülen veriler $\left(\mathrm{KT}_{\mathrm{MGM}}\right)$ için 0.312 ve 0.505 (ort. 0.420 ), YSA modeli ( $\mathrm{KT}_{\mathrm{YSA}}$ ) için 0.328 ve 0.524 (ort. 0.430 ), M1 modeli $\left(\mathrm{KT}_{\mathrm{M} 1}\right)$ için 0.360 ve 0.497 (ort. 0.433 ), $\mathrm{M} 2$ modeli $\left(\mathrm{KT}_{\mathrm{M} 2}\right)$ için 0.347 ve 0.489 (ort. 0.427 ), M3 modeli $\left(\mathrm{KT}_{\mathrm{M} 3}\right)$ için 0.313 ve 0.493 (ort. 0.418 ), M4 modeli $\left(\mathrm{KT}_{\mathrm{M} 4}\right)$ için 0.328 ve 0.507 (ort. 0.423 ) ve M5 modeli ( $\mathrm{KT}_{\mathrm{M} 5}$ ) için 0.328 ve 0.506 (ort. 0.421 ) olduğu görülmektedir. Antakya bölgesi için açıklık indeks değerlerinin minimum ve maksimum değerleri sirasiyla ölçülen veriler ( $\mathrm{KT}_{\mathrm{MGM}}$ ) için 0.297 ve 0.475 (ort. 0.402 ), YSA modeli için ( $\mathrm{KT}_{\mathrm{YSA}}$ ) için 0.287 ve 0.474 (ort. 0.404 ), M1 modeli $\left(\mathrm{KT}_{\mathrm{M} 1}\right)$ için 0.304 ve 0.475 (ort. 0.400 ), M2 modeli $\left(\mathrm{KT}_{\mathrm{M} 2}\right)$ için 0.357 ve 0.454 (ort. 0.417 ), M3 modeli $\left(\mathrm{KT}_{\mathrm{M} 3}\right)$ için 0.306 ve 0.472 (ort. 0.408$)$, M4 modeli $\left(\mathrm{KT}_{\mathrm{M} 4}\right)$ için 0.351 ve 0.454 (ort. 0.409) ve M5 modeli ( $\mathrm{KT}_{\mathrm{M} 5}$ ) için 0.386 ve 0.479 (ort. 0.399) olduğu görülmektedir. Kahramanmaraş bölgesi için de açıklık indeks değerlerinin minimum ve maksimum değerleri sırasıyla ölçülen ( $\mathrm{KT}_{\mathrm{MGM}}$ ) için 0.364 ve 0.610 (ort. 0.498 ), YSA modeli ( $\left.\mathrm{KT}_{\mathrm{YSA}}\right)$ için 0.375 ve 0.610 (ort. 0.507$)$, M1 modeli $\left(\mathrm{KT}_{\mathrm{M} 1}\right)$ için 0.424 ve 0.605 (ort. 0.517), M2 modeli $\left(\mathrm{KT}_{\mathrm{M} 2}\right)$ için 0.440 ve 0.589 (ort. 0.520 ), M3 modeli $\left(\mathrm{KT}_{\mathrm{M} 3}\right)$ için 0.387 ve 0.595 (ort. 0.501 ), M4 modeli $\left(\mathrm{KT}_{\mathrm{M} 4}\right)$ için 0.371 ve 0.615 (ort. 0.497 ) ve M5 modeli ( $\mathrm{KT}_{\mathrm{M} 5}$ ) için 0.442 ve 0.597 (ort. 0.516 ) olduğu görülmektedir.

\section{Sonuç ve Yorum}

Bu çalışmada, Gaziantep, Antakya ve Kahramanmaraş bölgeleri için aylık olarak yıllık güneş 1şınım şiddeti tahmin etmek için Meteoroloji Genel Müdürlügü̈'nden alınan on beş yıllık (1993-2007) ölçülmüş veriler kullanılarak bir tane YSA modeli ve beş tane de ampirik model geliştirilmiştir. Geliştirilen YSA mimari yapısı, on tane meteorolojik ve coğrafik veri girdi parametreli bir girdi katmanı, 4 ve 2 gizli nörondan oluşan iki gizli katmanı ve bir tane çıktı katmanından oluşan çok katmanlı ileri yayılımlı LevenbergMarquardt algoritmalı (trainlm) bir modeldir. Beş farklı ampirik modeller (M1-M5) ise Angström-Prescott-Page eşitliği kullanılarak geliştirilmiştir.

YSA ve ampirik formüllerden elde tahmin edilen global güneş enerji değerlerinin MGM'den alınan ölçülmüş değerler ile karşılaştırılması için $\mathrm{R}^{2}$, RMSE, MAPE ve MSE gibi dört gibi performans parametresi kullanılmıştır. YSA modeli için $\mathrm{R}^{2}$, RMSE, MAPE ve MSE sırasıyla Gaziantep için 0.990, 0.586, 4.105 ve 0.343, Antakya için 0.997, 0.287, 2.584, ve 0.083 ve Kahramanmaraş için $0.997,0.414,2.445$ ve 0.171 olarak bulunmuştur. İstatistiksel hata sonuçlarından görüldüğü gibi incelenen bölgeler için YSA modelinin başarılı ile gerçekleştiği görülmüştür.

Angström-Prescott eşitliği kullanılarak geliştirilen beş farklı modelden (M1-M5) elde edilen global güneş enerji değerlerinin MGM'den alınan ölçülmüş değerler ile karşılaştırılması sonucu $\mathrm{R}^{2}$, RMSE, MAPE ve MSE istatistiksel hata göstergeleri incelendiğinde, ortalama $\mathrm{R}^{2}$ değerleri sırasıyla Gaziantep bölgesi için 0.991, Antakya bölgesi için 0.985 ve Kahramanmaraş bölgesi için 0.992 olduğu görülmüştür. M1-M5 modellerden elde edilen değerlerin ölçülen değerlerle en iyi sonucu veren modeller Gaziantep ve Kahramanmaraş için Model $3\left(\mathrm{H}_{\mathrm{M} 3}\right.$, kübik $S / S o$ 'ye bağl1) olduğu görülürken, Antakya için model $5\left(\mathrm{H}_{\mathrm{M} 5}\right.$, kübik $S / S o$ 'ye ve bağıl neme bağl1) olduğu görülmüştür. Buna göre Model 3'den elde edilen değerler Gaziantep için $\mathrm{R}^{2}=0.993$, $\mathrm{RMSE}=0.480$ ve $\mathrm{MSE}=0.231$, Kahramanmaraş için $\mathrm{R}^{2}=0.994$, RMSE $=0.564$ ve MSE=0.318 olduğu görülürken Model 5'den Antakya için elde edilen değerler ise $\mathrm{R}^{2}=0.992, \mathrm{RMSE}=0.486$ ve $\mathrm{MSE}=0.219$ olduğu görülmüştür. 
Tablo 7. Ölçülen ve YSA ve ampirik eşitliklerden geliştirilen modellerden tahmin edilen aylık ortalama günlük açıklık endeksleri değerleri arasında karşılaştırılması $\left(\mathrm{K}_{\mathrm{T}}\right.$ : birimsiz)

\begin{tabular}{|c|c|c|c|c|c|c|c|c|c|c|c|c|}
\hline \multicolumn{13}{|c|}{ Gaziantep } \\
\hline & Oca & Şub & Mar & Nis & May & Haz & Tem & Ăgu & Eyl & Eki & Kas & Ara \\
\hline$K T_{M G M}$ & 0.315 & 0.323 & 0.419 & 0.417 & 0.440 & 0.486 & 0.495 & 0.502 & 0.505 & 0.457 & 0.373 & 0.312 \\
\hline$K T_{Y S A}$ & 0.328 & 0.331 & 0.398 & 0.397 & 0.465 & 0.509 & 0.506 & 0.515 & 0.524 & 0.475 & 0.381 & 0.336 \\
\hline$K T_{M I}$ & 0.360 & 0.376 & 0.398 & 0.420 & 0.446 & 0.484 & 0.495 & 0.497 & 0.485 & 0.456 & 0.420 & 0.364 \\
\hline$K T_{M 2}$ & 0.347 & 0.367 & 0.393 & 0.418 & 0.444 & 0.478 & 0.488 & 0.489 & 0.479 & 0.454 & 0.418 & 0.352 \\
\hline$K T_{M 3}$ & 0.313 & 0.340 & 0.376 & 0.410 & 0.444 & 0.483 & 0.492 & 0.493 & 0.484 & 0.456 & 0.410 & 0.319 \\
\hline$K T_{M 4}$ & 0.328 & 0.348 & 0.377 & 0.406 & 0.440 & 0.489 & 0.504 & 0.507 & 0.491 & 0.453 & 0.406 & 0.332 \\
\hline$K T_{M 5}$ & 0.330 & 0.370 & 0.380 & 0.408 & 0.434 & 0.497 & 0.506 & 0.494 & 0.481 & 0.434 & 0.390 & 0.328 \\
\hline \multicolumn{13}{|c|}{ Antakya } \\
\hline & Oca & Şub & Mar & Nis & May & Haz & Tem & Ăgu & Eyl & Eki & Kas & Ara \\
\hline $\mathrm{KT}_{M G M}$ & 0.297 & 0.337 & 0.400 & 0.412 & 0.457 & 0.475 & 0.439 & 0.454 & 0.470 & 0.414 & 0.355 & 0.311 \\
\hline$K T_{Y S A}$ & 0.292 & 0.352 & 0.409 & 0.418 & 0.447 & 0.468 & 0.448 & 0.463 & 0.474 & 0.426 & 0.363 & 0.287 \\
\hline$K T_{M I}$ & 0.304 & 0.336 & 0.371 & 0.395 & 0.426 & 0.459 & 0.475 & 0.474 & 0.464 & 0.418 & 0.362 & 0.320 \\
\hline$K T_{M 2}$ & 0.357 & 0.382 & 0.405 & 0.419 & 0.435 & 0.449 & 0.454 & 0.454 & 0.451 & 0.431 & 0.400 & 0.370 \\
\hline$K T_{M 3}$ & 0.306 & 0.348 & 0.387 & 0.412 & 0.440 & 0.463 & 0.472 & 0.471 & 0.466 & 0.433 & 0.378 & 0.327 \\
\hline$K T_{M 4}$ & 0.351 & 0.370 & 0.391 & 0.405 & 0.424 & 0.444 & 0.454 & 0.453 & 0.447 & 0.419 & 0.386 & 0.360 \\
\hline$K T_{M 5}$ & 0.286 & 0.341 & 0.387 & 0.401 & 0.438 & 0.479 & 0.466 & 0.448 & 0.469 & 0.431 & 0.351 & 0.288 \\
\hline \multicolumn{13}{|c|}{ Kahramanmaraş } \\
\hline & Oca & Şub & Mar & Nis & May & Haz & Tem & Ăgu & Eyl & Eki & Kas & Ara \\
\hline $\mathrm{KT}_{M G M}$ & 0.364 & 0.403 & 0.490 & 0.502 & 0.537 & 0.601 & 0.587 & 0.580 & 0.610 & 0.509 & 0.423 & 0.369 \\
\hline$K T_{Y S A}$ & 0.389 & 0.427 & 0.491 & 0.506 & 0.561 & 0.609 & 0.588 & 0.596 & 0.610 & 0.519 & 0.410 & 0.375 \\
\hline$K T_{M I}$ & 0.424 & 0.445 & 0.480 & 0.503 & 0.532 & 0.583 & 0.605 & 0.604 & 0.595 & 0.542 & 0.472 & 0.424 \\
\hline$K T_{M 2}$ & 0.440 & 0.461 & 0.492 & 0.512 & 0.535 & 0.574 & 0.589 & 0.588 & 0.582 & 0.543 & 0.485 & 0.440 \\
\hline$K T_{M 3}$ & 0.388 & 0.418 & 0.464 & 0.493 & 0.526 & 0.577 & 0.595 & 0.593 & 0.586 & 0.536 & 0.454 & 0.387 \\
\hline$K T_{M 4}$ & 0.372 & 0.400 & 0.447 & 0.478 & 0.516 & 0.586 & 0.615 & 0.613 & 0.601 & 0.530 & 0.436 & 0.371 \\
\hline$K T_{M 5}$ & 0.442 & 0.454 & 0.477 & 0.502 & 0.536 & 0.573 & 0.597 & 0.592 & 0.566 & 0.528 & 0.478 & 0.447 \\
\hline
\end{tabular}
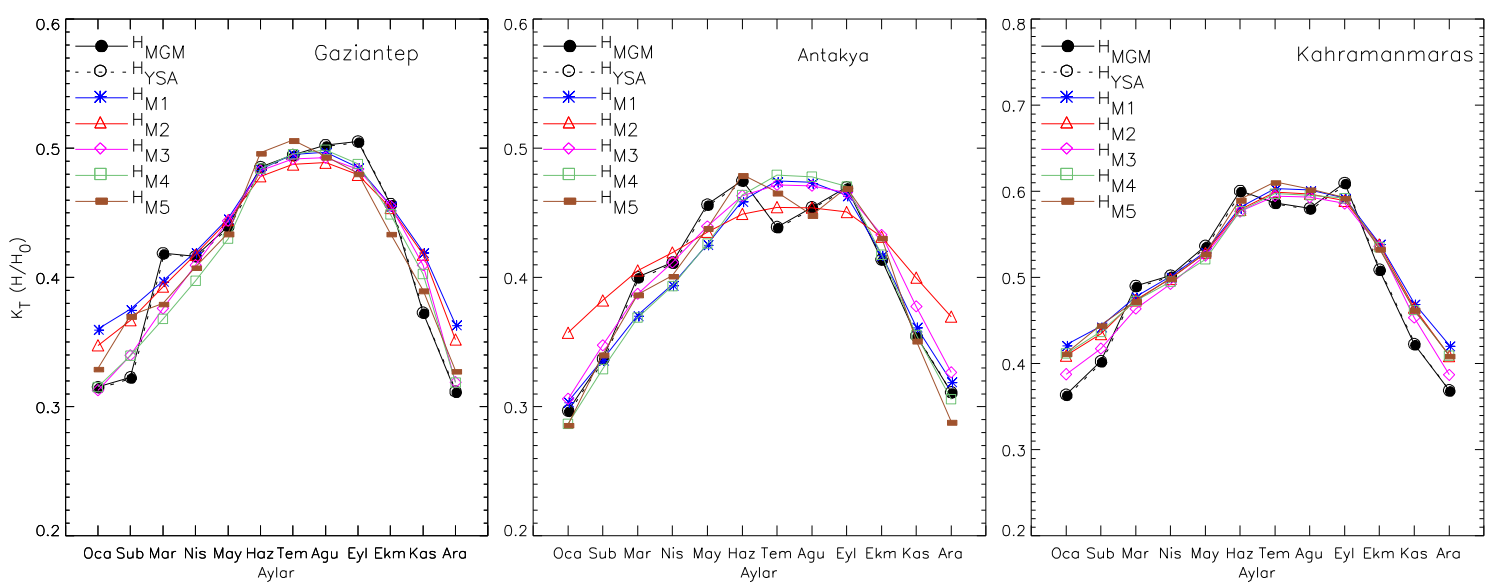

Şekil 8. $\mathrm{K}_{\mathrm{T}}$ 'nin gözlemlenen ve modellerden tahmin edilen aylık ortalama günlük değerleri arasında karşılaştırılması

Ayrıca, MGM'den alınan ölçülmüş ve YSA ile her üç bölge için ampirik formüllerden tahmin edilen en uygun ( $\left.\mathrm{KT}_{\mathrm{M} 1-\mathrm{M} 5}\right)$ aylık global güneş enerji değerleri için açıklık indeksleri $\left(\mathrm{KT}=\mathrm{H} / \mathrm{H}_{0}\right)$ tek tek hesaplanmıştır. Gaziantep için ölçülmüş verilerden, YSA modelinden ( $\mathrm{KT}_{\mathrm{YSA}}$ ) ve en iyi ampirik modelden elde edilen açıklık indeksleri sırasıyla $0.328<\mathrm{KT}_{\mathrm{MGM}}<0.505,0.328<\mathrm{KT}_{\mathrm{YSA}}<0.524$ ve $0.313<\mathrm{KT}_{\mathrm{M} 3}<0.493$ aralığında, Antakya için $0.297<\mathrm{KT}_{\mathrm{MGM}}<0.475,0.287<\mathrm{KT}_{\mathrm{YSA}}<0.474$ ve $0.386<\mathrm{KT}_{\mathrm{M} 5}<0.479$ aralığında ve 
Kahramanmaraş için $\quad 0.364<\mathrm{KT}_{\mathrm{MGM}}<0.610, \quad 0.375<\quad \mathrm{KT}_{\mathrm{YSA}}<0.610 \quad$ ve $0.387<\mathrm{KT}_{\mathrm{M} 3}<0.595$ aralığında olduğu görülmüsstür.

Sonuç olarak, hem YSA modelinden ( $\left.\mathrm{H}_{\mathrm{YSA}}\right)$ hem de geliştirilen modellerden $\left(\mathrm{H}_{\mathrm{M} 1}-\mathrm{H}_{\mathrm{M} 5}\right)$ hesaplanan güneș 1şınım şiddet değerleri ile ölçülen gerçek değerler $\left(\mathrm{H}_{\mathrm{MGM}}\right)$ arasında bir uyum olduğunu göstermektedir. YSA yöntemlerinin geleneksel regresyon modellerine kıyasla güneş radyasyonunu tahmin etmek için daha uygun olduğunu göstermiştir. Geliştirilen bu modellerin benzer iklime sahip bölgelerde kullanılabileceği önerilmektedir.

\section{Araştırmacıların Katkı Oranı Beyanı}

Muhittin ŞAHAN: Araştırma, Veri Temini, Orjinal Taslak Yazımı, İnceleme ve Düzenleme

\section{Çatışma Beyanı}

Bu çalışmanın yazarları olarak herhangi bir çatışma beyanımız bulunmadığıı bildiririz.

\section{Etik Kurul Onayı ve Aydınlatılmış Onam Bilgileri}

$\mathrm{Bu}$ çalışmanın yazarları olarak herhangi bir etik kurul onayı ve/veya aydınlatılmış onam bilgileri beyanımız bulunmadığını bildiririz.

\section{Kaynakça}

[1] M. A. AbdulAzeez, "Artificial neural network estimation of global solar radiation using meteorological parameters in Gusau, Nigeria," Archives of Applied Science Research, 3 (2), 586595, 2011.

[2] E.A. Ahmed and M. El-Nouby Adam, "Estimate of global solar radiation by using artificial neural network in Qena, Upper Egypt," Journal of Clean Energy Technologies, 1, 2, 2013.

[3] O. Şenkal and T. Kuleli, "Estimation of solar radiation over Turkey using artificial neural network and satellite data," Applied Energy, 86, 1222-1228, 2009.

[4] O. Senkal "Modeling of solar radiation using remote sensing and artificial neural network in Turkey," Energy, 35 (12), 4795-4801, 2010.

[5] M. Şahan ve Y. Okur, "Akdeniz Bölgesine ait meteorolojik veriler kullanılarak yapay sinir ağları yardımıyla güneş enerjisinin tahmini," Süleyman Demirel Üniversitesi Fen Edebiyat Fakültesi Fen Dergisi, 11 (1), 61-71, 2016.

[6] A. Angström, "Solar and terrestrial radiation," Quarterly Journal of the Royal Meteorological Society, 50 (210), 121-126, 1924.

[7] J. A. Prescott, "Evaporation from a water surface in relation to solar radiation," Transactions of the Royal Society of South Australia, 64, 114-148, 1940.

[8] M. R. Rietveld, "A new method for estimating the regression coefficients in the formula relating solar radiation to sunshine," Agricult. Meteorol., 19, 243-252, 1978.

[9] H. Ogelman, A. Ecevit, and E. Tasdemiroglu, "A new method for estimating solar radiation from bright sunshine data," Solar Energy, 33, 619-625, 1984.

[10] K. L. Bristow and G. S. Campbell, "On the relationship between incoming solar radiation and daily maximum and minimum temperature," Agric. For. Meteorol., 31, 159-166, 1984.

[11] B. G. Akınoglu and A. Ecevit, "A further comparison and discussion of sunshine based models to estimate global solar radiation," Solar Energy, 15, 865-872, 1990.

[12] R. De Jong and D. W. Stewart, "Estimating global solar radiation from common meteorological observations in western Canada," Can. J. Plant. Sci. 73, 509-518, 1993.

[13] B. T.Nguyen and T. L. Pryor, "The relationship between global solar radiation and sunshine duration in Vietnam," Renewable Energy, 11, 47-60, 1997.

[14] I. T. Togrul, H. Togrul, and D. Evin, "Estimation of global solar radiation under clear sky radiation in Turkey," Renewable Energy, 21, 271-287, 2000.

[15] S. A. Khalil and A. M. Fathy, "An empirical method for estimating global solar radiation over Egypt," Acta Polytechnica, 48 (5), 48-53, 2008. 
[16] S. Edalati, M. Ameri, and M. Iranmanesha, "Estimating and modeling monthly mean daily global solar radiation on horizontal surfaces using artificial neural networks in South East of Iran," Journal of Renewable Energy and Environment (JREE), 2 (1), 36-42, 2015.

[17] I. A. Basheera and M. Hajmeer, "Artificial neural networks: fundamentals, computing, design, and application," Journal of Microbiological Methods, 43, 3-31, 2000.

[18] F. S. Marzano, E. Fionda, and P. Ciotti, "Neural-network approach to ground-based passive microwave estimation of precipitation intensity and extinction," Journal of Hydrology, 328, 121$131,2005$.

[19] D. Graupe, Principles of Artificial Neural Networks. (2nd Edition), Advanced series on circuits and systems, volume 6, World Scientific Publishing Co. Pte. Ltd., 2007.

[20] C. Gershenson, "Artificial neural networks for beginners, formal computational skills teaching package," COGS, University of Sussex, Brighton, UK, 2001.

[21] J. K. Page, "The estimation of monthly ea values of daily total short wave radiation on vertical and inclined surfaces from sunshine records for latitudes $40^{\circ} \mathrm{N}-40^{\circ} \mathrm{S}$," Proceedings of the UN Conference on New Sources of Energy, Paper No. 598, 378-390, 1964.

[22] S. Klein, "Calculation of monthly average insolation on tilted surfaces," Solar Energy, 19 (4), 1977, 325-329, 1977.

[23] M. Iqbal, An Introduction to Solar Radiation. London: Academic Press, 1983.

[24] J. A. Duffie and W. A. Beckman, Solar Engineering of Thermal Processes. (4th ed.), John Wiley and Sons, Inc., New York, 2013.

[25] J. R. Howell, R. B. Bannerot, and G. C. Vliet, Solar-Thermal Energy Systems Analysis and Design. McGraw-Hill, Inc., New York, 1982.

[26] M. Despotovic, V. Nedic, D. Despotovic, and S. Cvetanovic, "Review and statistical analysis of different global solar radiation sunshine models," Renewable and Sustainable Energy Reviews, 52, 1869-1880, 2015. 